\title{
ARQUEOLOGÍA DE LA CUENCA DEL RÍO MOLLEBAMBA, ANTABAMBA-APURÍMAC
}

\author{
Pieter VAN Dalen LUnA \\ Universidad NACIONAL MAYOR DE SAN MARCoS \\ pvandalen2@hotmail.com \\ HAMiLTON ObRegón PiLLACa \\ UniversidAd NACIONAL SAN CRISTÓBAL DE HUAMANGA \\ hamilpillaca@hotmail.com \\ ANGÉLICA López CARHUAS \\ UnIVERSIDAD NACIONAL SAN LUIS GONZAGA DE ICA \\ alopezcarhuas@gmail.com \\ Joe Huamaní Perlacios \\ UNIVERSIDAD NACIONAL MAYOR DE SAN MARCOS \\ johuper@hotmail.com
}

\section{RESUMEN}

El presente artículo presenta las características de los asentamientos prehispánicos ubicados en ambas márgenes del río Mollebamba, ubicado en las cuatro comunidades campesinas que conforman el distrito de Juan Espinosa Medrando, en la provincia de Antabamba. Los asentamientos, pertenecen a diferentes periodos culturales, desde sitios precerámicos hasta el Tawantinsuyu, con una mayor presencia de asentamientos del Intermedio Tardío. La información presentada en el presente trabajo es de gran importancia por cuanto son los primeros antecedentes arqueológicos de esta provincia tan poco investigada.

Palabras claves: Arqueología, Antabamba, Mollebamba, Tawantinsuyu.

\section{Abstract}

This article presents the characteristics of prehistoric settlements on both banks of the river Mollebamba located in four rural communities that make up the district Juan Espinosa Medrano in the province of Antabamba. The settlements, belonging to different cultural periods, from preceramic sites to Tawantinsuyu, with a greater presence of Late Intermediate settlements. The information 
presented in this work is of great importance because they are the first archaeological history of this province so little investigated.

KeYwords: Archeology, Antabamba, Mollebamba, Tawantinsuyu.

\section{INTRODUCCIÓN}

La provincia de Antabamba es una de las siete provincias que forman parte del departamento de Apurímac, en la sierra centro sur peruana. Esta provincia está surcada por dos cuencas principales, el río Antabamba y el río Mollebamba que desagua en el primero por su margen izquierda, tras recorrer los terrenos de las cuatro comunidades campesinas del distrito de Juan Espinosa Medrano.

En términos culturales, posee una gran cantidad de sitios arqueológicos de diferentes periodos culturales, predominando los de las culturas Huari, Aymaraes y Tawantinsuyu. Así, encontramos grandes pueblos o marcas, poblados menores, áreas funerarias, cuevas, sitios con quillqas, caminos, infraestructura hidráulica, sitios ceremoniales, abrigos rocosos, andenes, entre otros.

En esta oportunidad presentamos cerca de 40 sitios arqueológicos nuevos, ubicados en el ámbito del distrito de Juan Espinosa Medrano, registrados en el marco del proyecto de catastro e Inventario del patrimonio Cultural de la Provincia de Antabamba, financiado por el Vicerrectorado de Investigación de la Universidad nacional mayor de San Marcos, a través d elos proyectos con-con de investigación.

\section{UBICACIÓN}

La cuenca del río Mollebamba se encuentra ubicado en el extremo sur de la provincia de Antabamba, en la jurisdicción de las cuatro comunidades campesinas que conforman el distrito de Juan Espinosa Medrano. Se trata de un territorio conformado por tres áreas fisiográficas: el fondo del valle, las laderas escarpadas y la altiplanicie o puna, cada una con características y recursos bióticos particulares.

\section{Sitios Arqueológicos del Distrito de Juan Espinoza Medrano}

Se ha identificado a nivel del distrito de Juan Espinosa Medrano un total de 39 sitios arqueológicos, correspondientes a diferentes periodos de ocupación prehispánico.

\section{A. Sitios Arqueológicos de la Comunidad Campesina de Mollebamba CAlvario:}

Ubicación: Se encuentra ubicado en la margen derecha del río Mollebamba, sobre ceja y ladera noreste del cerro Calvario, de formación rocosa. Políticamente se ubica en la estancia de Rayuda, Comunidad Campesina de Mollebamba, distrito de Juan Espinoza Medrano, provincia de Antabamba. Se localiza en las coordenadas UTM: 0727017E, 8402261N, a 4305 metros de altitud sobre el nivel del mar. El terreno donde se emplaza el sitio arqueológico está cubierto de vegetación arbustiva espinosa, cactácea y de vegetación gramínea, identificándose las siguientes plantas: ancoquishca, chilco, taya, salqa, ccera, entre otras plantas de nombre no identificado. El pueblo de Mollebamba se ubica a 45 minutos en vehículo por trocha carrozable, hacia el lado oeste. 


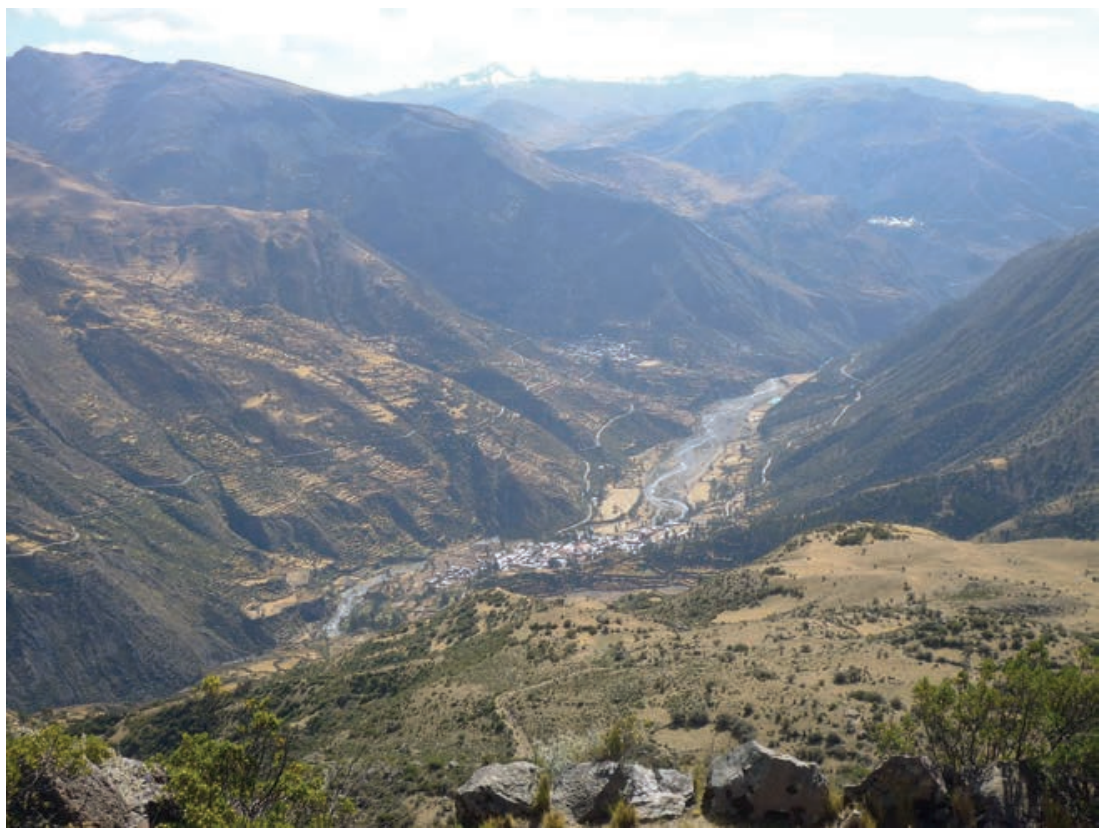

Figura 1: Vista panorámica de las comunidades de Mollebamba, Silco y Vito.

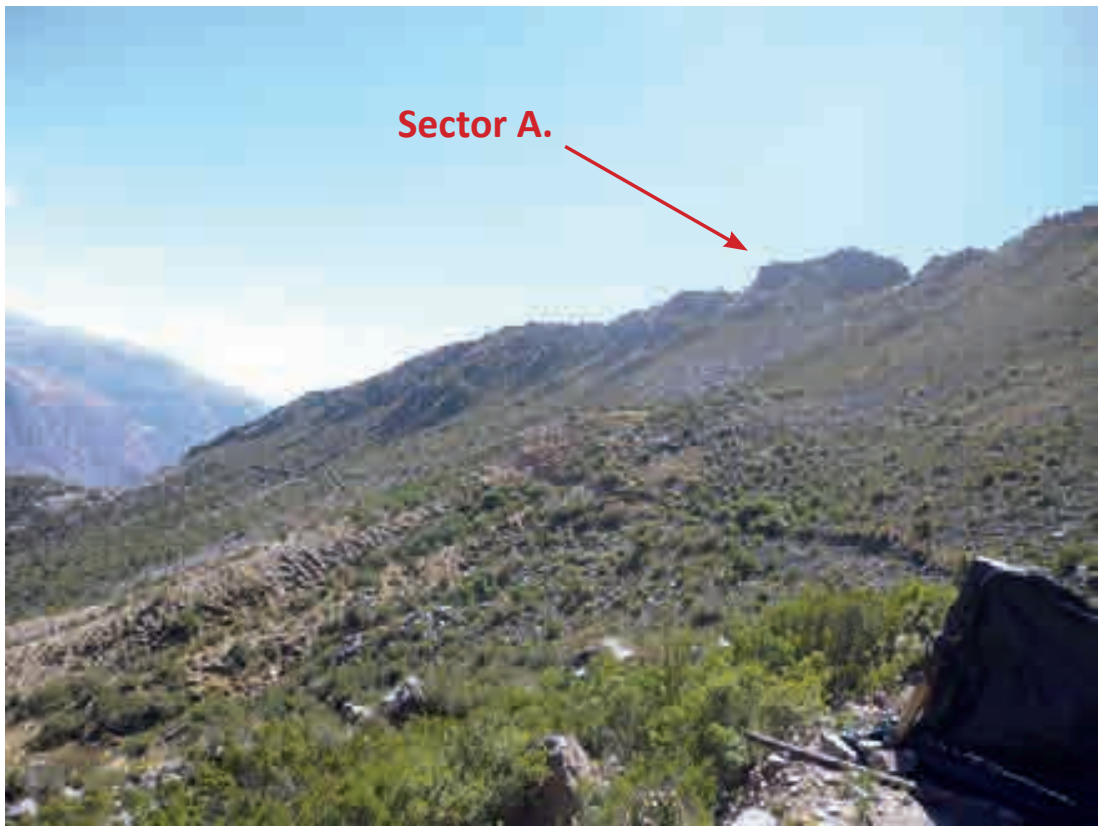

Figura 2: Vista panorámica de la cresta del cerro Calvario, donde se sitúa el sitio prehispánico. 


\section{Componentes del Sitio: el Sitio Está Conformado por dos Sectores:}

Sector A: Ubicado en la parte superior o cima del cerro Calvario, dispuesto en un eje este-oeste. Se aprecia en este sector, un conjunto de edificaciones de planta cuadrangular e irregular de dimensiones regulares, elaborado con piedras canteadas y angulosas del lugar, de dimensiones medianas y pequeñas. En algunos casos se conserva el mortero o argamasa, en otros se presenta sin mortero por erosión del agua de temporadas de lluvia. Estas edificaciones están emplazadas sobre lecho rocoso, los basamentos se instalaron cortando la superficie de terreno hacia el subsuelo. Uno de los recintos
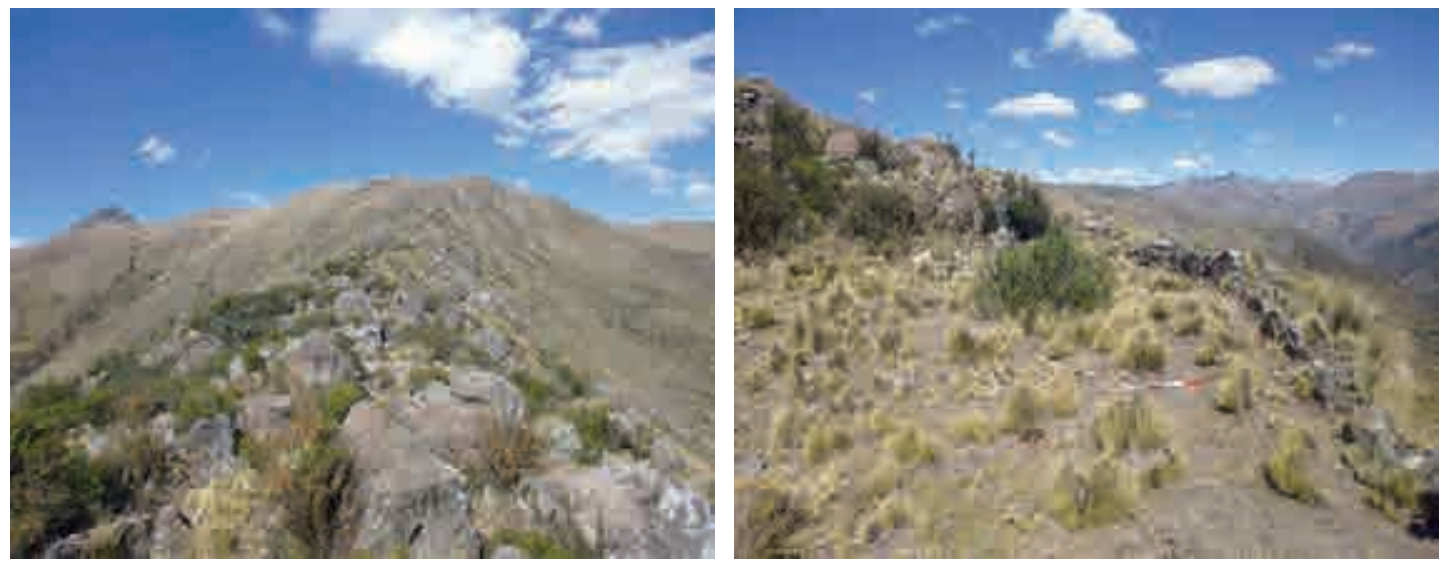

Figura 3: Izquierda: Vista panorámica de oeste a este del sitio arqueológico Calvario, donde se observa como está emplazado en una cima rocosa. Figura 4: Derecha: detalle de un muro de contención, asentado en el lado oeste de la ceja.
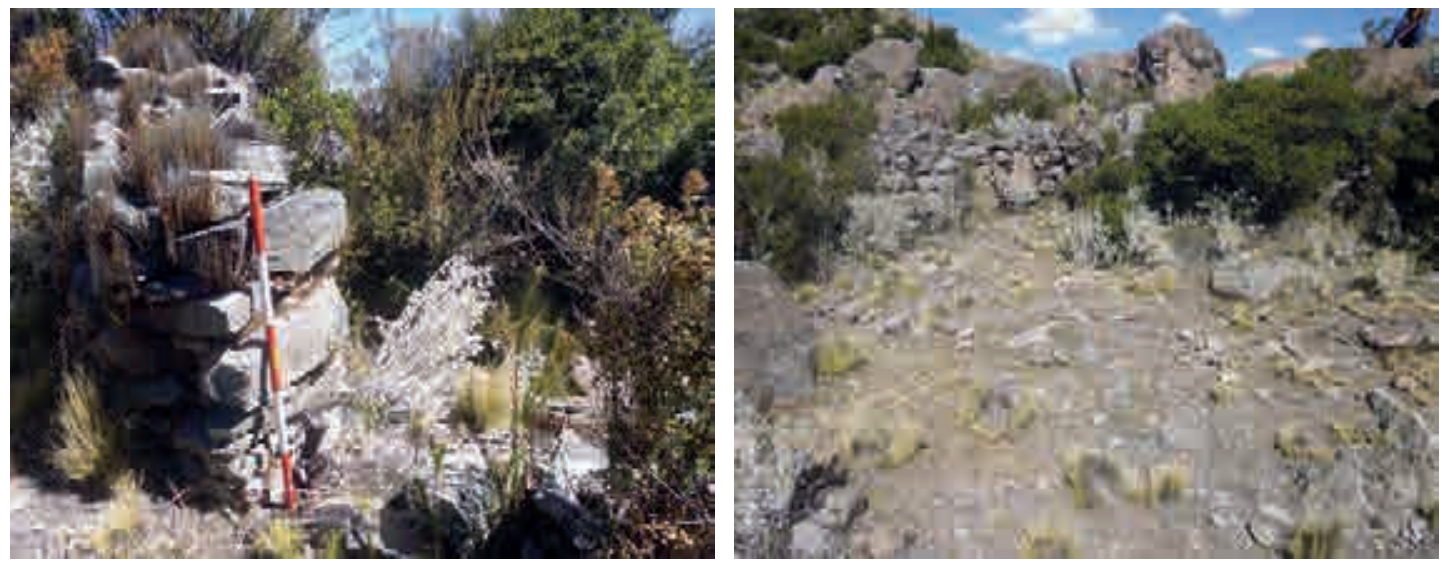

Figura 5: Izquierda: detalle, donde se observa el paramento más conservado de un acceso. Figura 6: Derecha: Vista de una estructura circular.

mejor conservados, tiene un diámetro de 5.00 metros de ancho (eje norte-sur), por 6.05 metros de largo (eje este-oeste); donde el muro más conservado adquiere las siguientes medidas: $1.50 \mathrm{~m}$ de alto y $0.50 \mathrm{~m}$ de grosor. Se identificó en más de un recinto el vano de acceso con orientación al noreste y al sur. Algunos vanos no se identificaron debido al pésimo estado de conservación. El vano mejor conservado tiene $0.65 \mathrm{~m}$ de alto, $0.50 \mathrm{~m}$ de ancho por $0.50 \mathrm{~m}$ de grosor. En medio del sector se observa nu- 
merosos afloramientos rocosos grandes, algunos recintos se hallan adosados a estas rocas. En todo el tramo de la cima del sector A, se evidencia recintos con características similares: el 90\%, tienen plata cuadrangular y ovalada, mientras el 10\% presentan planta irregular y en D. La mayoría se encuentran en pésimo estado de conservación, lo que no permite la identificación exacta. En el lado noroeste del sector, junto a los recintos, se halló un abrigo rocoso de $0.60 \mathrm{~m}$ de alto, $1.80 \mathrm{~m}$ de ancho y $2.50 \mathrm{~m}$ de profundidad, de forma irregular ovalado, al interior se identificó material óseo humano, correspondiente a un área de enterramiento colectivo en estado de conservación deteriorado. Se identificó restos óseos humanos (costilla, fémur y otros), no se identificó cráneo. Hacia el lado noreste de la parte baja del sector, continúa el desplazamiento de estructuras circulares de dimensiones más grandes.

Hacia el extremo noreste del sector ya finalizando el sitio, sobre un espacio de relieve empinado, se identificó una muralla en sentido este-oeste, donde presenta mayor grado de verticalidad de sus paramentos laterales. El tramo de este muro presenta mayor tecnología constructiva, compuesto con piedras canteadas grandes y medianas, con pachillas intermedias y unido con mortero mezclado con grava. El área mejor conservada de la muralla tiene $2.50 \mathrm{~m}$ de altura, $0.90 \mathrm{~m}$ de ancho y $6.00 \mathrm{~m}$ de largo, con orientación este-oeste. El estado de conservación del total de la muralla es pésima, el 90 \% presenta desplome y grietas.

Sector B: Se encuentra ubicado inmediatamente hacia el lado noreste del sector A, sobre la ladera que desciende hacia una quebrada. En este sector se observan edificaciones de planta circular e irregular, aglutinados, en medio de una tupida vegetación arbustiva espinosa, cactácea y gramínea. Se observan algunas unidades arquitectónicas emplazadas sobre terrazas naturales y plataformas artificiales, construidas con muros de mampostería ordinaria construidas con piedras naturales del lugar unidas con argamasa de barro, con muros de 0.40 a $0.50 \mathrm{~m}$ de ancho, $0.55 \mathrm{~m}$ de alto. La estructura más grande tiene un diámetro de $5 \mathrm{~m}$, de muros al 90\% destruido, no observándose vanos de acceso.

Tipo de sitio: Asentamiento doméstico y administrativo.

Filiación cultural: La primera ocupación del sitio corresponde a finales de Horizonte Medio, con reocupación en el Intermedio Tardío.

Materiales culturales: La prospección determinó la existencia de estructuras arquitectónicas, emplazadas en plataformas naturales en la cima o al filo del cerro (sector A), y ladera noreste (sector B), donde la mayoría de los recintos fueron acondicionados a espacios artificiales que fueron rellenados al parecer de muros de contención emplazados desde extremo norte-sureste.

En cuanto a materiales muebles en superficie se identificó fragmentos de cerámica diagnóstica, con diseños de líneas horizontales de color negro sobre pasta de color rojizo, correspondiente al Intermedio Tardío; así como fragmentos no diagnósticos, artefactos líticos y óseo humano, en poca proporción.

Estado de conservación: Malo. Las edificaciones están muy destruidas, principalmente por agentes antrópicos y naturales. El pastoreo de animales en la zona ha hecho colapsar los paramentos. De igual manera, el sismo del año 2001 destruyó gran parte del asentamiento. El principal problema es el colapso de muros. El sitio se encuentra destruido al $95 \%$.

\section{CCONOPANI}

Ubicación: Se encuentra ubicado en la margen derecha del río Mollebamba, valle alto, a 500 metros aproximadamente al oeste del sitio arqueológico Calvario, emplazado sobre una lomada de dimensión mediana. Políticamente se ubica en el paraje de Cconopani, estancia Rayuda, Comunidad 
Campesina de Mollebamba, distrito de Juan Espinoza Medrano, provincia de Antabamba. Se localiza en las coordenadas UTM: 0724167E, 8407929N, a 3992 metros de altitud sobre el nivel del mar. El terreno donde se emplaza el sitio arqueológico está cubierto la mayor parte de vegetación arbustiva espinosa, cactácea en la parte alta y en la parte baja cercano a fuente de agua se evidencia cubierto de pastos llamado chocco de relieve casi plano. Los espacios habitacionales adquieren planta irregular, ovalada y en algunos casos de planta casi cuadrangular, en la que comparten los recintos guardan una similitud o patrón arquitectónico similar al sitio arqueológico Calvario. El río Mollebamba se ubica a 45 minutos en carro hacia el lado oeste. Hacia el lado noroeste presenta una fuerte pendiente rocosa, tupida de vegetación arbustiva. El área del sitio es utilizado como área de pastoreo.

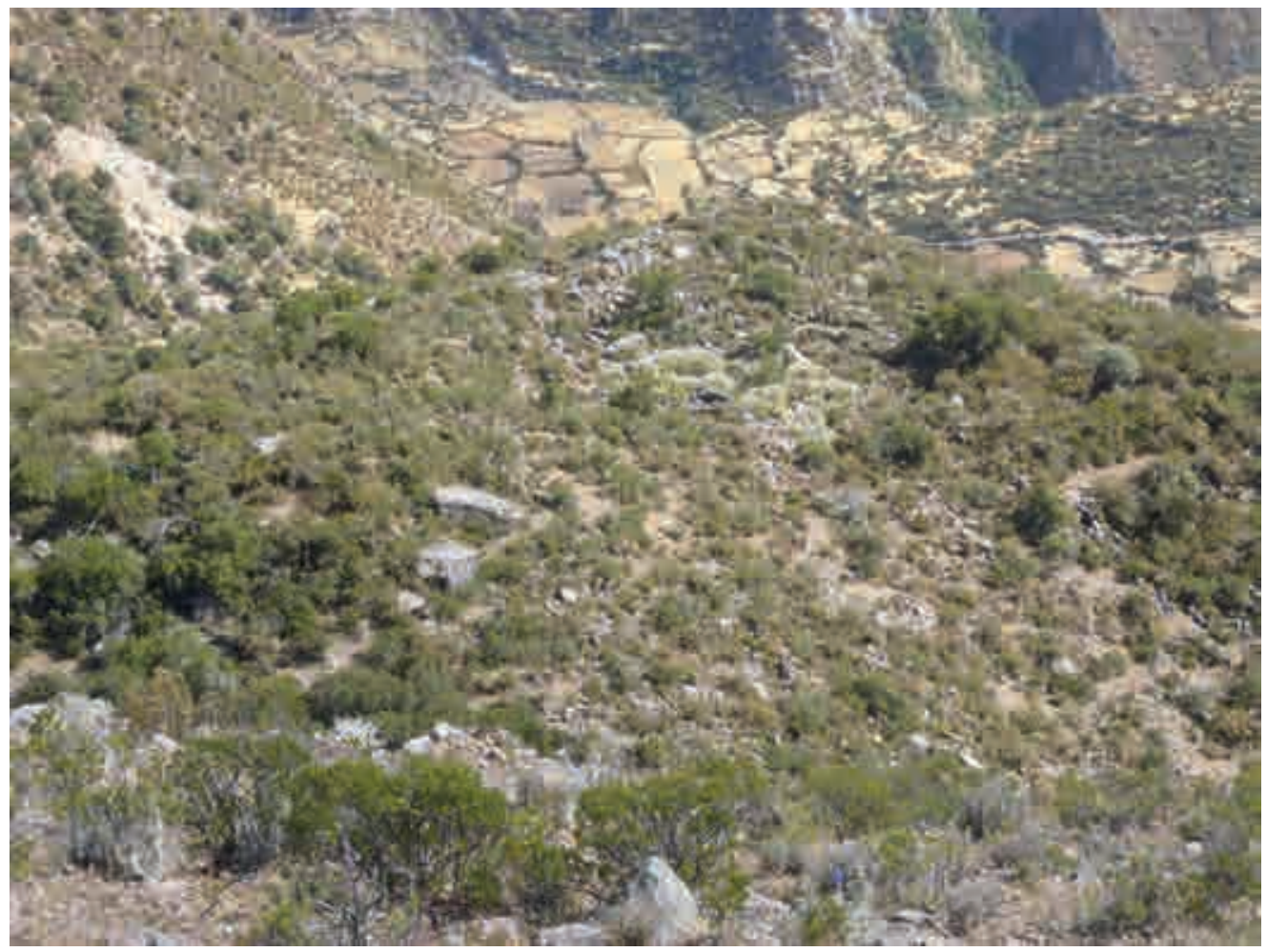

Figura 7: Vista de Cconopani desde el Cerro Calvario.

La vía de acceso es mediante trocha carrozable desde Mollebamba en un tramo de 45 minutos, la cual llega hasta la parte alta del sitio. La fuente de agua próxima se ubica a 200 metros aproximadamente al norte del sitio, se trata de un bojedal que tiene curso en sentido este-oeste, denominado por los pobladores fuente de agua Rayuda. El sitio arqueológico tiene un área aprox. de una hectárea y media.

Componentes del sitio: El sitio arqueológico denominado Cconopani presenta dos sectores.

Sector A: Está conformado por un área doméstica ubicada en la parte superior de la lomada Cconopani. Las edificaciones domésticas generalmente adquieren plantas irregulares y en excepciones 
ovaladas, adosados a unidades más pequeñas, los muros son a doble hilera, edificados en base de piedras canteadas del lugar, unidas con argamasa de barro, los recintos tienen de 4 a 5 metros de ancho por 5 a 6 metros de largo, con muros de $0.50 \mathrm{~m}$ de grosor y entre $0.90 \mathrm{~m}$ a $2 \mathrm{~m}$ de alto.
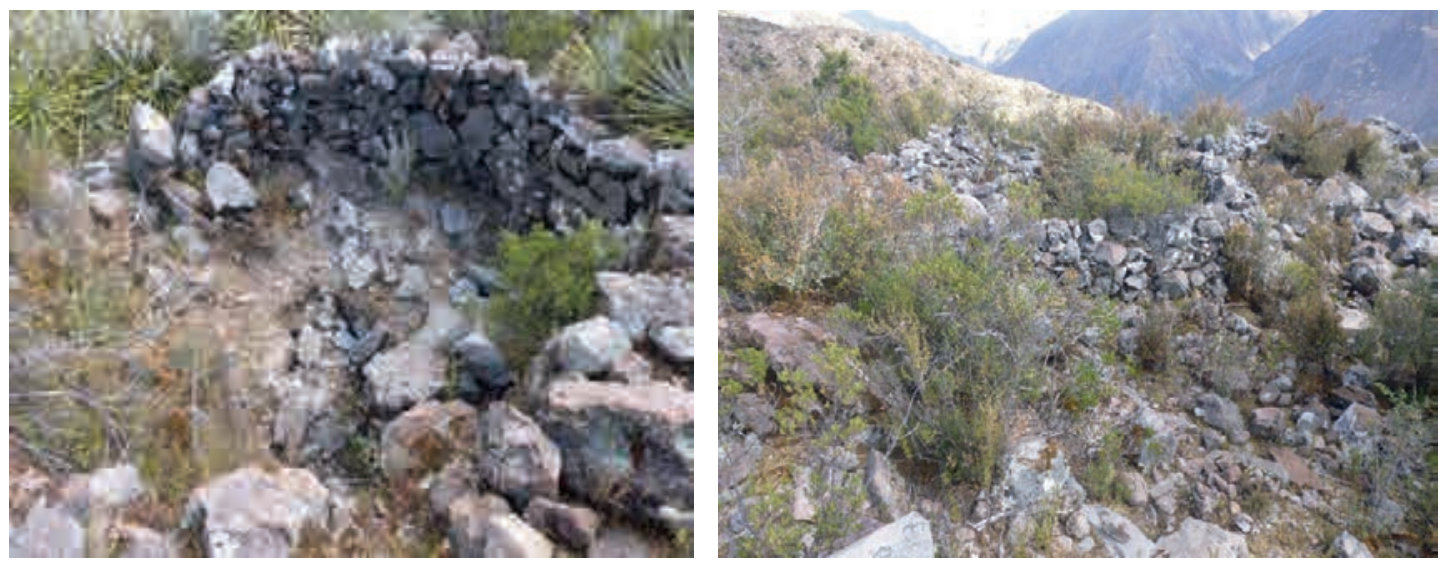

Figura 8 (izquierda): Vista de detalle de un recinto con esquinas ovaladas. Figura 9 (derecha): Recintos aglutinados, donde se observa de forma ovalada.
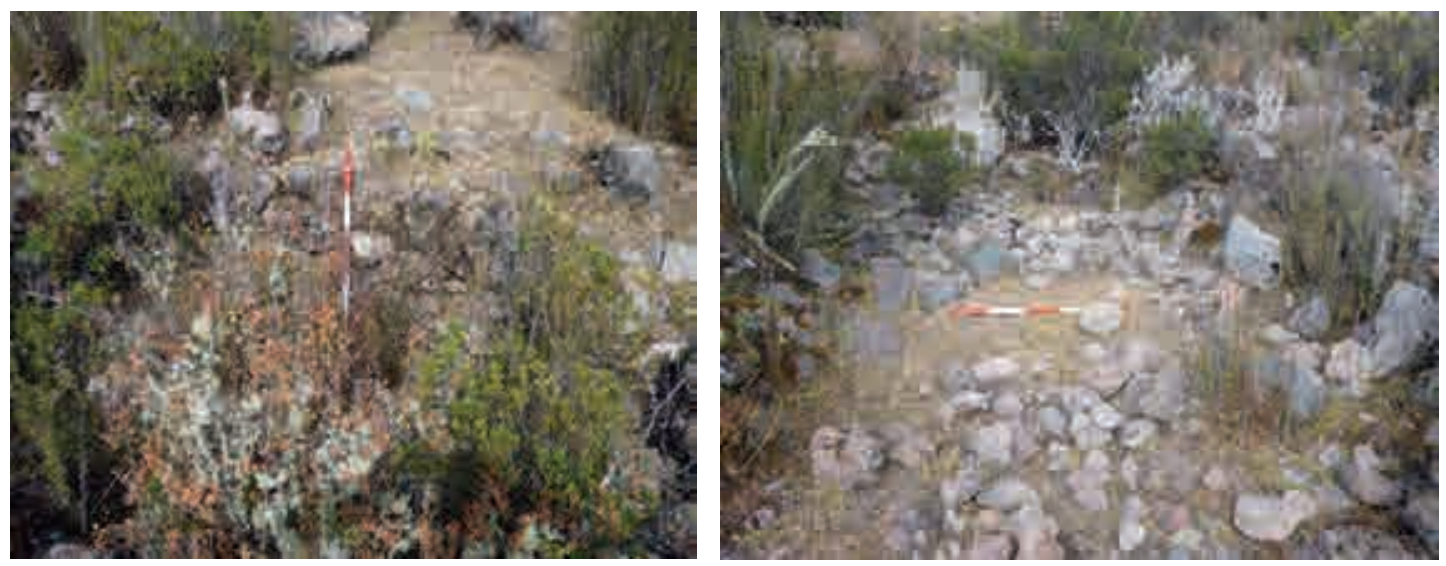

Figura 10 (izquierda): Vista interior de un paramento de muro. Figura 11 (derecha): Acceso principal.

La mayoría de recintos presentan los vanos de acceso orientados hacia el lado norte, con un ancho de 0.80 metros y 0.80 metro de alto, elaborados con piedras canteadas unidas con argamasa y con presencia de pachillas. Del total de recintos, el $4 \%$ tiene planta cuadrangular, el $2 \%$ tienen planta ovalada, mientras que el resto son de planta irregular. Las estructuras cuadrangulares y los de planta ovalada se encuentran adosados a las estructuras irregulares. En este sector se ha identificado alrededor de 50 recintos aproximadamente, de los cuales el 90\% están destruidos.

Sector B: Está conformado por un área de terrazas ubicado en la parte superior media del sitio Cconopani, inmediatamente al norte del sector A. Está conformado por andenes conformados por 15 
terrazas aproximadamente, escalonadas e interrumpidos, donde los seccionamientos se alinean en sentido este-oeste; en algunos casos asociado a estructuras domésticas. La agricultura desarrollada era por riego teniendo como fuente un puquio muy cercano. En promedio, las terrazas tienen muros de contención de un 1 metro de alto y 0.60 metros de grosor, mientras que el ancho de la terraza tiene un promedio de seis metros. Actualmente se utilizan las terrazas con fines de pastoreo de ganado.

Tipo de sitio: Doméstico y andenes.

Filiación cultural: El sitio corresponde al Intermedio Tardío.

Materiales culturales: Durante la prospección se determinó la existencia de estructuras arquitectónicas emplazadas en terrazas naturales ubicados en la cima de Cconopani (sector A) y en la parte superior media (sector B). Algunos recintos se acondicionan a espacios naturales o artificiales, rellenados a través de muros de contención, emplazados en la cresta este-oeste de Cconopani. En superficie no se identificó materiales muebles.

Estado de conservación: Malo. Las causas de deterioro son naturales, como la vegetación que debilita la arquitectura, creando fisuras y rajaduras; así también se hallan colapsado y destruido por el sismo del año 2001. Entre las causas antrópicas figuran el pastoreo de ganado de la zona. Los recintos se hallan desplomados en un $90 \%$ y pérdida de mortero por erosión pluvial, un 4\% presentan pandeo.

\section{HuacllakuQ Rumi}

Ubicación: Se encuentra ubicado en la margen derecha del río Mollebamba, valle alto, a 500 metros de distancia aproximadamente al sur de del sitio arqueológico Cconopani. Políticamente se ubica en el paraje de Huacllakuq Rumi, estancia Rayuda, Comunidad Campesina de Mollebamba, distrito de Juan Espinoza Medrano, provincia de Antabamba. Se localiza en las coordenadas UTM: 0726841E, $8401673 \mathrm{~N}$, a 3959 metros de altitud sobre el nivel del mar. El terreno donde se emplaza el sitio arqueológico es de pendiente moderada, con gran cantidad de bloques de rocas de arenisca con cuarzo, aparentemente parece una cantera donde se elaboró bloques de piedras con fines constructivos, donde las áreas colindantes al sitio están cubiertas de vegetación herbácea (ichu, chocco y otros). La fuente de agua más cercana al sitio es un puquial ubicado a de 200 metros del sitio, en el lado noreste.

El río Mollebamba se ubica hacia el lado oeste. Hacia el noroeste del sitio hay una fuerte pendiente rocosa, de tupida vegetación arbustiva. El área del sitio es utilizada como área de pastoreo de ganados.

La vía de acceso es mediante trocha carrozable desde el pueblo de Mollebamba, en un tramo de 45 minutos, para luego tomar una vía pedestre de 10 minutos hacia el lado oeste. El sitio arqueológico tiene un área aprox de 200 metros de radio.

Componentes del sitio: El sitio arqueológico denominado Huacllakuq Rumi presenta dos sectores:

Sector A: Está conformado por un espacio abierto de planta cuadrangular, a modo de un patio asociada a dos grandes rocas desprendidas de la parte alta del cerro. El espacio tiene 8 metros de largo (eje este-oeste) por 6 metros de ancho (eje norte-sur). Este patio presenta un muro perimétrico de $1.40 \mathrm{~m}$ de alto y $0.50 \mathrm{~m}$ de ancho. El $80 \%$ de este muro está colapsado.

Sector B: Está conformado por un abrigo rocoso conteniendo al interior tres estructuras funerarias con arquitectura y sin arquitectura. El abrigo rocoso está emplazado en un terreno de ligera pendiente rocosa, inmediatamente al oeste del sector A, el acceso está cubierto de vegetación arbustiva y de ichu. Las estructuras funerarias identificadas son: 


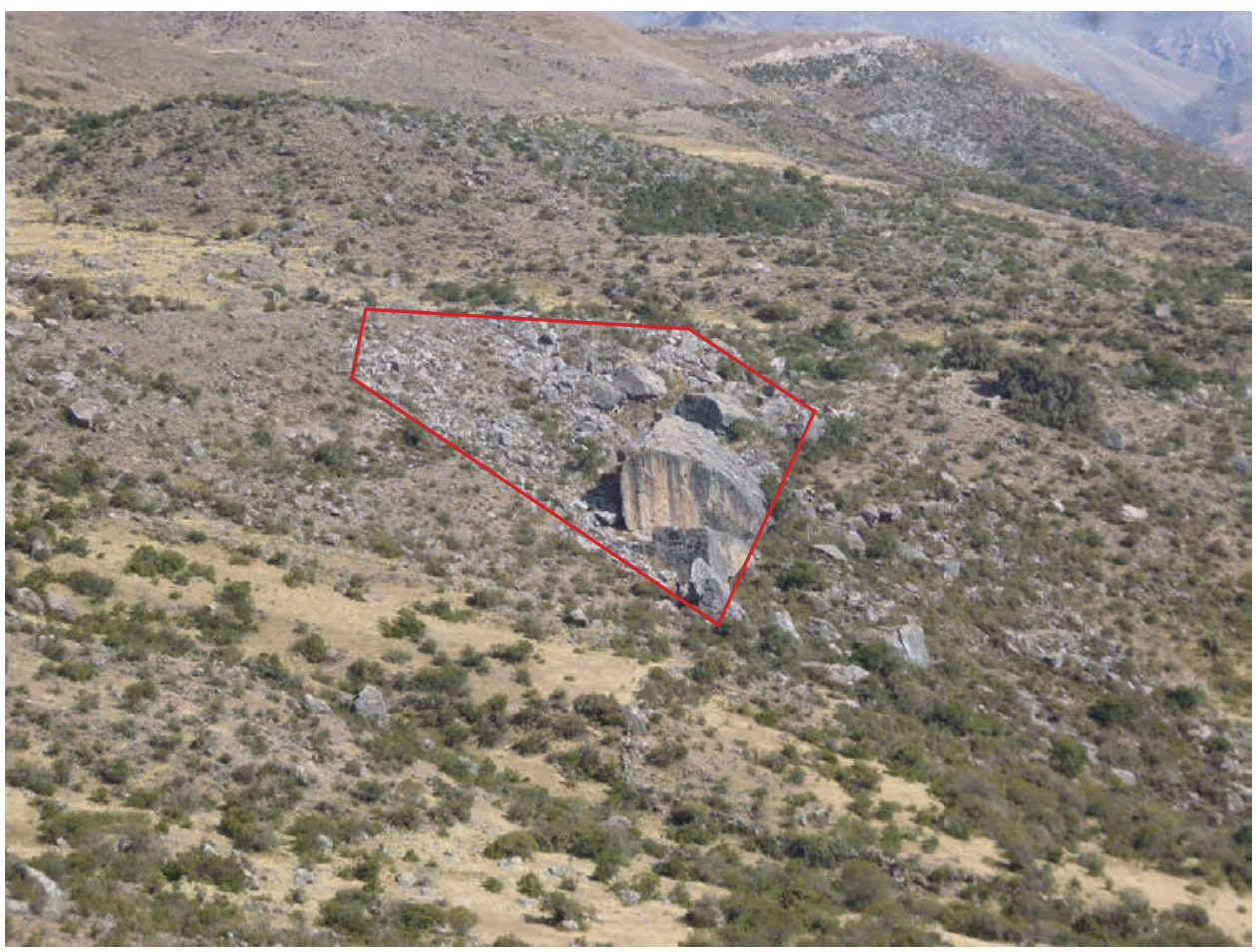

Figura 12: panorámica del sitio arqueológico Huacllakuq rumi, vista desde Cconopani.
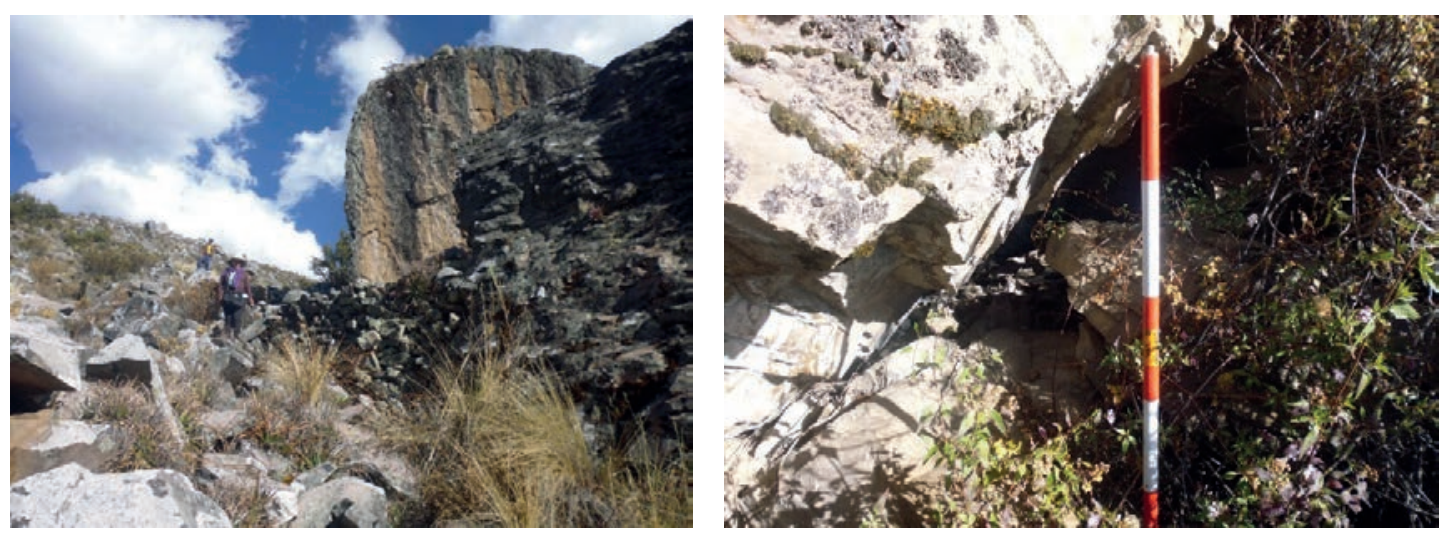

Figura 13 (izquierda) detalle del muro adosado a los dos bloques de roca. Figura 14 (derecha): Vista panorámica de la roca, donde se elaboró las estructuras funerarias.

- Estructura funeraria 1: Es de planta ovalada, sin arquitectura y disturbada. Tiene $0.50 \mathrm{~m}$ de ancho, $0.70 \mathrm{~m}$ de largo y $0.20 \mathrm{~m}$ profundidad, al interior se ubicó un pequeño fragmento de textil color anaranjado (1x1) sin decoración, material óseo humano (cráneo, fémur, carpos y metacarpos), un fragmento de material cerámico doméstico con hollín y una soguilla trenzada y elaborada a base de fibra vegetal. 
- Estructura funeraria 2: adosado al interior del abrigo rocoso, ubicado al sur de la estructura funeraria 1, contigua a esta. La estructura funeraria es de planta ovalada, de 1.15 a $1.20 \mathrm{~m}$ de diámetro, con un ancho de muro de $0.45 \mathrm{~m}$ por $1.00 \mathrm{~m}$ de alto. El muro está edificado a base de piedras canteadas unidas con argamasa de barro. Los paramentos interno y externo presentan tarrajeo y enlucido. Al interior se observó varios cráneos humanos, lo que evidencia que la tumba contenía entierros múltiples; algunos de estos cráneos presentan evidencias de callosidades producto de lesiones premorten. No se identificó materiales muebles al interior. Esta estructura funeraria, al igual que las otras dos se encuentran huaqueadas.

- Estructura funeraria 3: Ubicado inmediatamente al sur de la estructura funeraria 2; tiene $0.30 \mathrm{~m}$ de alto, $0.90 \mathrm{~m}$ de ancho y $1.00 \mathrm{~m}$ de largo. Se halló al interior restos óseos humanos de varios individuos, lo que evidencia que contenía un entierro colectivo. No presenta arquitectura funeraria, ni se identificó interna o externamente restos de materiales culturales muebles. Las tres estructuras funerarias están asociadas y son contemporáneas.

Tipo de sitio: Área ceremonial y funeraria.

Filiación cultural: Los dos sectores corresponden al periodo Intermedio Tardío, probablemente con uso continuo hasta el Horizonte Tardío.

Materiales culturales: Se halló en superficie fragmentos de cerámica doméstica de pasta tosca, de superficie exterior alisada y con engobe de color rojo oxidante. También se observó material óseo humano, material textil y una soguilla de fibra vegetal.

Estado de conservación: Malo. Las causas de deterioro son naturales y antrópicas (pastoreo de ganado de la zona y huaqueo). Las estructuras funerarias se encuentran destruidas en un $99 \%$ por huaqueo.
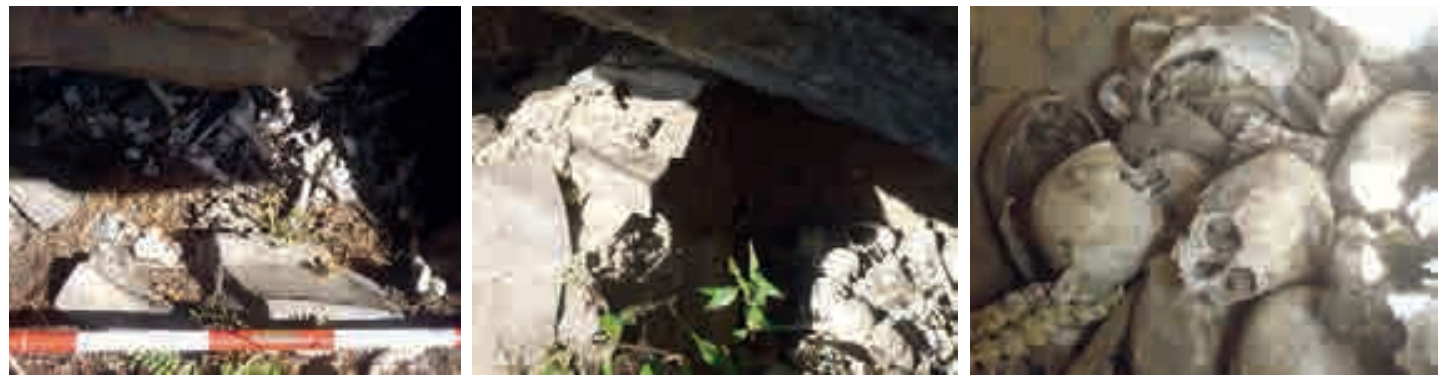

Figura 15 (izquierda): Vista al interior de la estructura funeraria 1. Figura 16 (centro): Vista al interior de la estructura funeraria 2. Figura 17 (derecha): Vista de cráneos humanos al interior de la estructura funeraria 2.

\section{Mauca LLacta}

Ubicación: Se encuentra ubicado en la margen derecha del río Mollebamba, en el valle medio. Políticamente se ubica en el paraje de Mauca Llacta, estancia Capaq Ccocha, Comunidad Campesina de Mollebamba, distrito de Juan Espinoza Medrano, provincia de Antabamba. Se localiza en las coordenadas UTM: 0724067E, 8407919N, a 3899 metros de altitud sobre el nivel del mar. Ubicado en una cima rocosa, sobre una lomada de relieve casi plano por el lado este. El terreno donde se emplaza el sitio está cubierto de vegetación arbustiva espinosa y cactácea. El manejo del espacio se ciñe prin- 
cipalmente a la cima del cerro, conformado por espacios habitacionales, andenes, plazas, tumbas, corrales y un tramo de camino. Los espacios habitacionales generalmente son irregulares de forma circular u ovalada y en algunos casos excepcionales de planta en D. Hacia el lado oeste presenta una fuerte pendiente rocosa con vista al río Mollebamba. El área del sitio es utilizado actualmente como área de pastoreo y de cultivo.

La vía de acceso es mediante una trocha carrozable desde Mollebamba en un tramo de 20 minutos, la cual llega hasta la parte alta del sitio. La fuente de agua próxima al sitio se ubica a 500 metros al noreste en el lugar denominado Chillahuani Ccocha. El sitio arqueológico tiene un área aprox. de dos hectáreas.

Componentes del sitio: El sitio arqueológico Mauca Llacta presenta cinco sectores.

Sector A: Está conformado por un área doméstica con estructuras irregulares en la cima de la lomada. Las edificaciones domésticas generalmente adquieren plantas irregulares y de formas circulares, ovaladas y cuadrangulares, de 5 a 6 metros de diámetro, con muros de 0.50 metros de ancho por 0.90 metros de alto. Algunos recintos están adosados entre sí. Hay además, algunos de planta en D de menor dimensión (de 3 a 4.50 metros de diámetro al medio). Los muros son dobles, edificados en base de piedras canteadas del lugar, unidas con argamasa de barro.

La mayoría de recintos presentan los vanos de acceso orientados hacia el lado norte, con un ancho de 0.80 metros, 0.60 metros de grosor, por 1.00 metro de alto elaborados con piedras trabajadas unidas con pachillas, dando uniformidad de aparejo en la cara principal de los muros. Del total de recintos, el $4 \%$ tiene planta cuadrangular, el 2\% tienen planta ovalada, el $2 \%$ en D, mientras que el resto son de planta irregular. Las estructuras cuadrangulares y los de planta ovalada se encuentran adosados a las estructuras irregulares. En este sector se ha identificado alrededor de 72 recintos, de los cuales el 90\% tiene un pésimo estado de conservación. Algunos recintos parecen aglutinados y otros cuentan con vías de acceso a modo de corredores que miden 1.30 metros de ancho. Las estructuras arquitectónicas se asocian a patios irregulares de 5 a 7 metros de largo.

Sector B: Está conformado por una cista funeraria subterránea asociada a estructuras arquitectónicas domésticas. La cista está ubicada al interior de un patio. Tiene 0.35 metros de radio, 0.53 metros de profundidad y el ancho de muro es de $0.33 \mathrm{~m}$. Los muros de la cista están elaborados con piedras medianas unidas con mortero de barro, hallándose al interior un fragmento cerámico de pasta tosca, de superficie exterior alisada de color rojo pálido, conocido por los lugareños como chomba (pulido). La cista subterránea está profanada.

Sector C: Está conformado por terrazas ubicadas en la parte superior de los sectores A y B, en el lado sureste, los seccionamientos de andenes se desplazan en sentido norte-sur de manera discontinua o interrumpidos, conformado aprox por 30 graderías de andenerías, las terrazas tienen en promedio 1.00 metro de alto y 3 metros de ancho como máximo, el estado de conservación de los paramentos es pésimo, algunos son reutilizados para el sembrío actual de los lugareños y sirve como corrales de ganado.

Sector D: conformado por numerosos corrales de 10 metros de ancho por 15 metros de largo, algunos se asocian a estructuras domésticas y a un tramo de camino que entra por el lado norte, generalmente carecen de acceso.

Sector E: Conformado por un tramo de camino prehispánico que entra al sitio Mauca Llacta por el lado norte. Junto a este camino se identificó las bases de estructuras circulares, asociadas también a espacios abiertos a modo de plazas. En superficie se halló material cerámico del Horizonte Tardío, la 


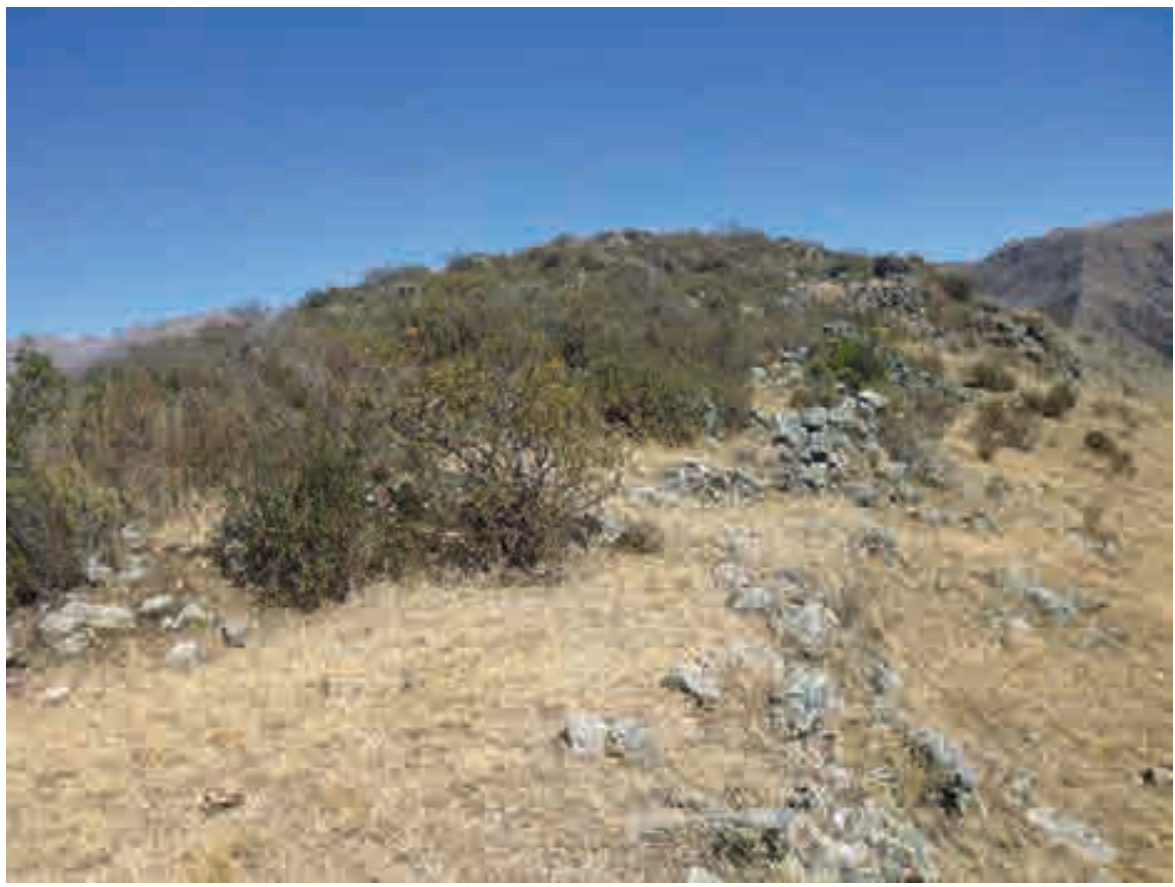

Figura 18: vista panorámica norte sur, donde se observa el sitio arqueológico.
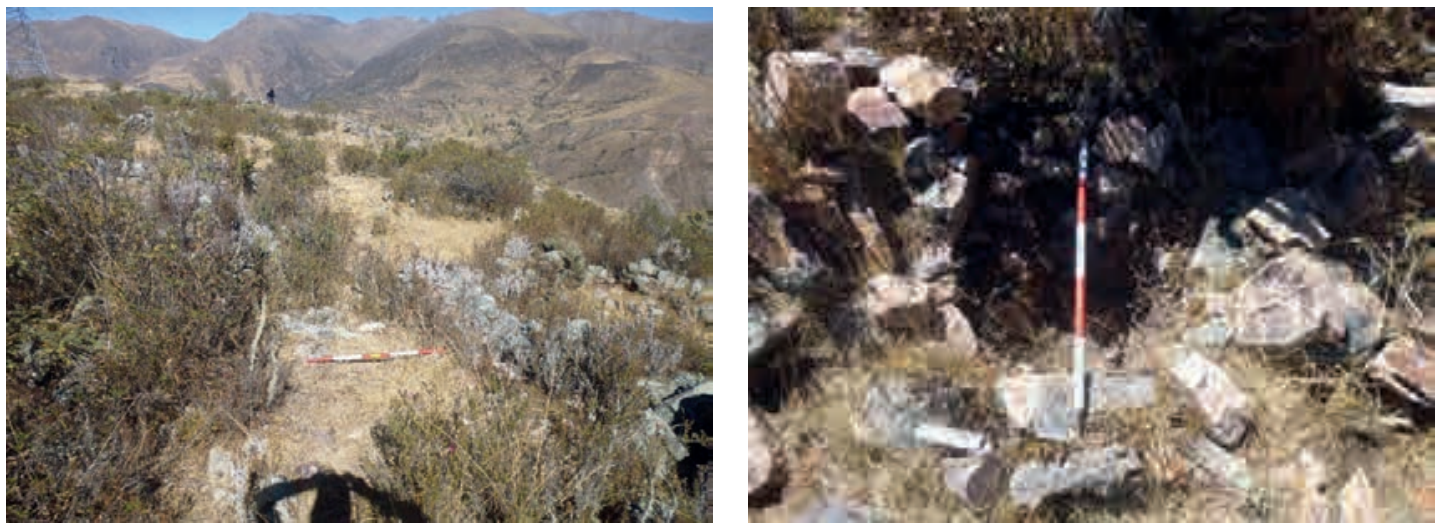

Figura 19 (izquierda): Vista panorámica sur norte, donde se observa los conjuntos arquitectónicos. Figura 20 (derecha): Foto detalle de una cista subterránea, adosado a un recinto.

muestra más representativa está conformado por fragmentos de engobe de color naranja, pasta compacta de color naranja y marrón. Los bordes son de labio redondeado, su tratamiento de superficie exterior e interior es alisado. El ancho del camino es de 2 metros.

La descripción de estos sectores a lo largo de toda la zona de Mauca Llacta, expresa espacios bien distribuidos propio de los asentamientos del Intermedio Tardío, ocupados hasta el Tawantinsuyu con 
distribución de áreas domésticas, ceremonial, productivas y áreas de circulación que reflejan un manejo del espacio de carácter urbano.

Tipo de sitio: Centro Poblado.

Filiación cultural: El sitio corresponde al Intermedio Tardío y Horizonte Tardío.

Materiales culturales: Se identificó en superficie fragmentería cerámica, material lítico conformado por batanes y una mano de moler.

Estado de conservación: Malo. Las causas de deterioro son naturales como la erosión de la vegetación que debilita la arquitectura, creando fisuras y rajaduras; así mismo desplomes por el sismo del año 2001. Entre las causas antrópicas figuran el pastoreo de ganado en la zona y actualmente se continúa realizando la actividad agrícola en espacios abiertos. Los recintos se hallan desplomados y con pérdida de mortero por erosión pluvial y viento en un $90 \%$, un $4 \%$ presentan pandeo y lagunas, un $10 \%$ de recintos están huaqueados.

Observaciones. La zona doméstica o residencial en el lado suroeste sufrió fuerte afectación por la colocación de una torre de alta tensión.

\section{TORRE TORREYCCO}

Ubicación: Se encuentra ubicado en la margen derecha del río Mollebamba, hacia el lado norte del pueblo. Políticamente se ubica en el paraje de Torre Torreycco, estancia Pata Patayuk, Comunidad Campesina de Mollebamba, distrito de Juan Espinoza Medrano, provincia de Antabamba. Se localiza en las coordenadas UTM: 0724202E, 8408489N, a 3783 metros de altitud sobre el nivel del mar. El terreno donde se emplaza el sitio consta de tres terrazas o niveles naturales, de acuerdo a la geografía del terreno, nivel uno lomada con pendiente pronunciada, hacia el lado norte está cubierto de vegetación arbustiva espinosa y cactácea; nivel dos, cima más alta donde se ubica el sitio torre Torreycco por el lado noroeste presenta un acantilado con vista al río Mollebamba; nivel tres, en la parte de mayor elevación, por toda la ceja o cresta que continúa en sentido norte - sur. El manejo del espacio se ciñe principalmente a la parte media superior, cima y cresta del cerro Torre Torreycco, conformado por espacios habitacionales, terrazas y tumbas de múltiples funciones. El área del sitio es utilizado como cerco para pastoreo de ganado.

La vía de acceso es mediante camino herradura que dura aproximadamente 30 minutos de caminata desde el sitio Mauca Llacta, la cual llega hasta la parte alta del sitio. La fuente de agua próxima al sitio se ubica a pocos metros, bofedal denominado Pata Patayuk. El sitio arqueológico tiene un área aprox. de dos hectáreas y media.

Componentes del sitio: Los espacios habitacionales son de planta irregular, circular u ovalada, cuadrangulares (casi el 10\%) y en algunos casos excepcionales de planta en D. La mayoría de espacios habitacionales adquieren un patrón arquitectónico muy similar al sitio de Mauca Llacta. Todo el perímetro de la zona arqueológica se encuentra amurallado. La muralla es doble a base de piedras canteadas unidas con mortero de barro y pachillas, con aparejo casi perfecto en la cara superior de los muros, de 2.50 metros de alto máximo por 0.80 metros de grosor de muro. Esta muralla o muro perimétrico por la zona sureste presenta remodelación moderna. El sitio arqueológico Pata Patayuk presenta cuatro sectores:

Sector A: Está conformado por 9 terrazas emplazadas en toda la ladera rocosa, que se desplaza hacia la parte alta del sitio. Las terrazas se desplazan de manera escalonada, ubicado en el lado sures- 
te del sitio. Los seccionamientos de andenes se desplazan en sentido norte-sur de manera continua. Las terrazas tienen en promedio 1.20 metros de alto y 6 metros de ancho como máximo, 10 metros de largo y un ancho de muro de 0.60 metros. El estado de conservación de los paramentos es pésimo, algunos son reutilizados para el sembrío actual de los lugareños y sirve como pastizales de ganado. En la parte alta se asocian a estructuras arquitectónicas ovaladas.

Sector B: Está conformado por un área doméstica de estructuras irregulares, cuadrangulares y en $\mathrm{D}$, la concentración de los recintos se encuentra en el primer nivel de la montaña rocosa, cubierto de vegetación arbustiva espinosa y cactácea. Las edificaciones domésticas generalmente adquieren plantas irregulares, de forma circular u ovalada y cuadrangulares; de 5 a 6 metros de diámetro, el
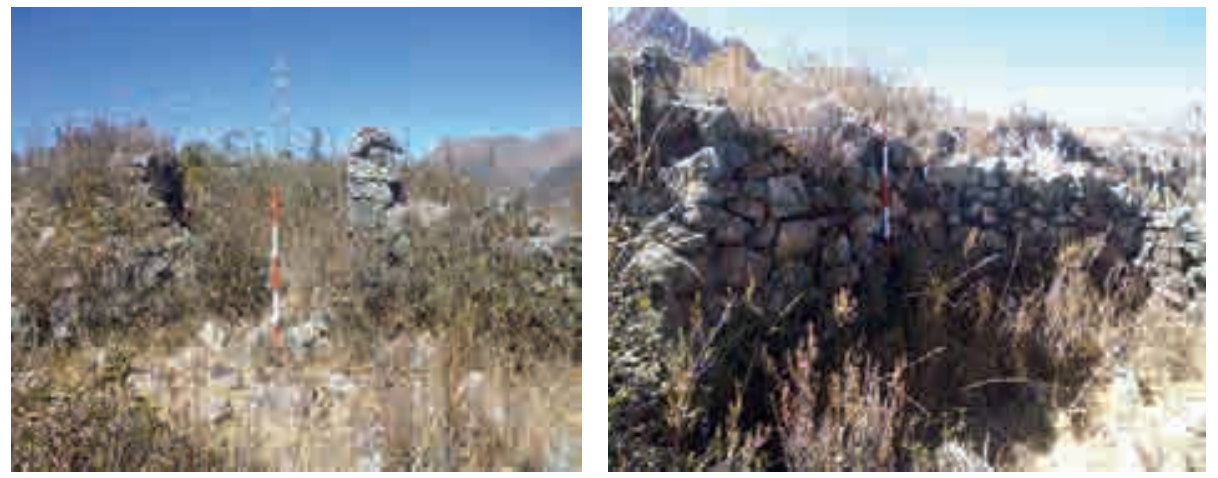

Figura 21 (izquierda): Detalle de un recinto. Figura 22 (derecha): detalle de la cara interior del paramento, donde se observa un recinto de forma irregular.

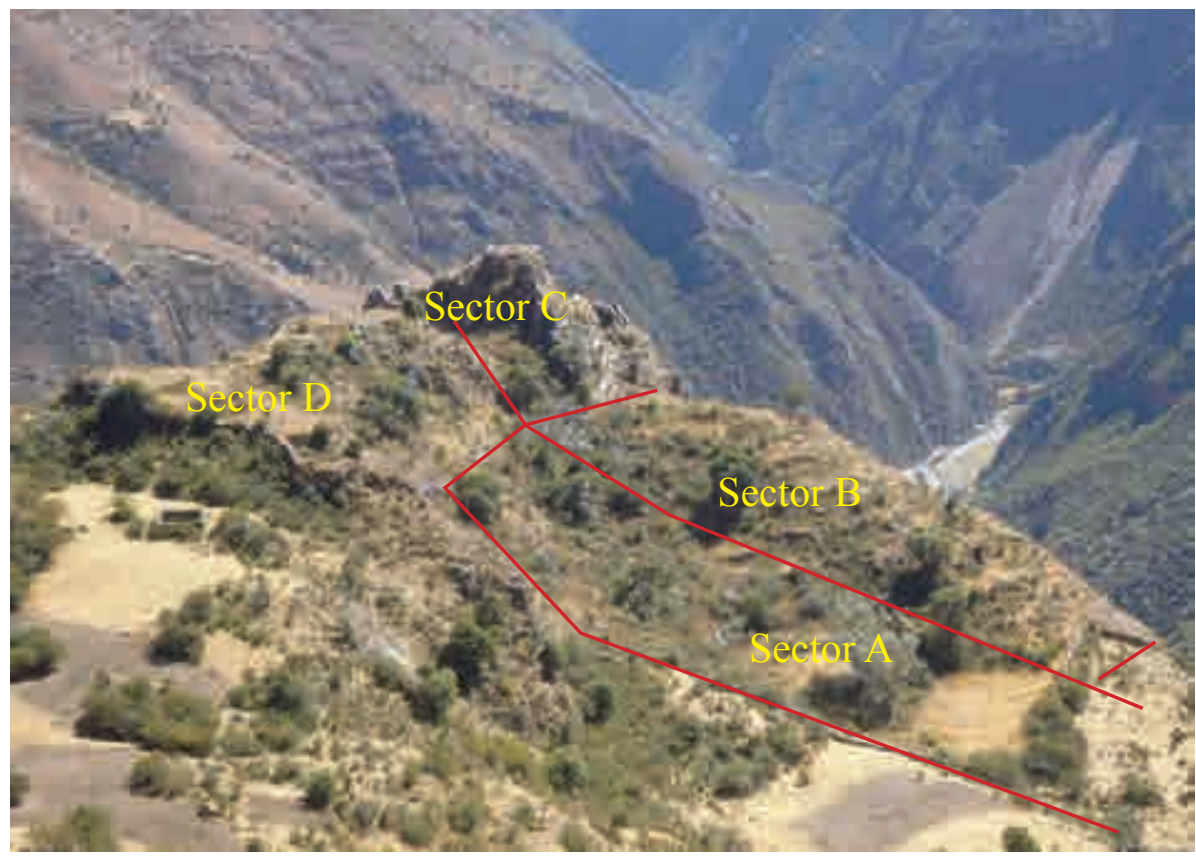

Figura 23: vista panorámica del sitio arqueológico Torreyuk, desde el sitio Mauca Llacta. 

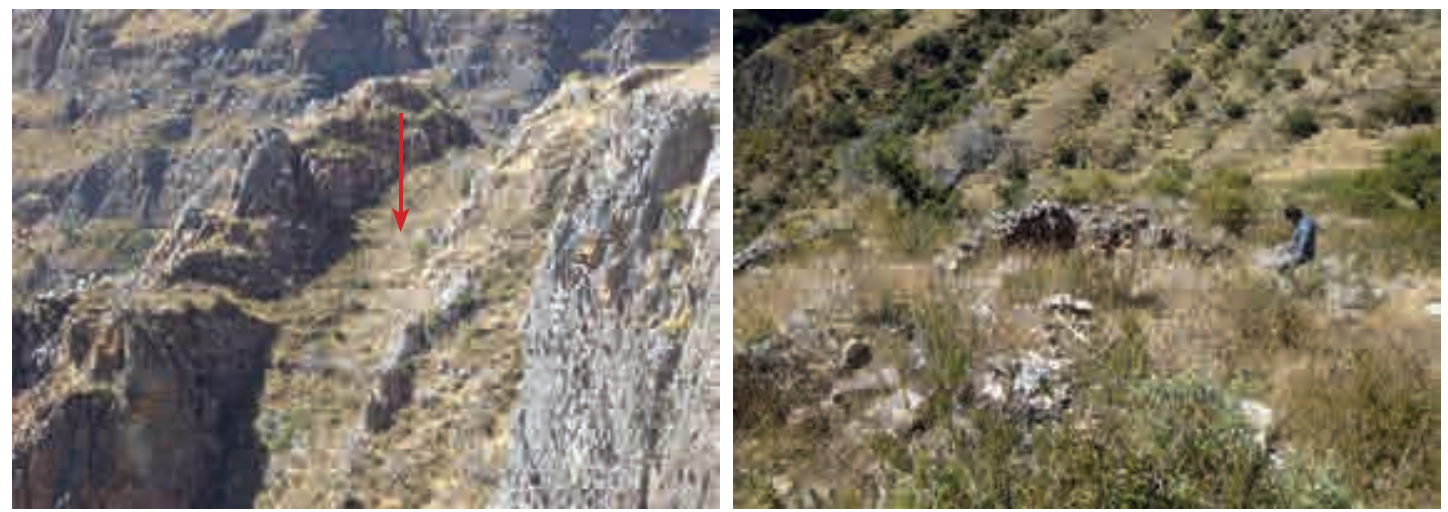

Figura 24 (izquierda): Vista del lado oriente, donde se observa desplazamiento de andenes. Figura 25 (derecha): detalle del sector $\mathrm{B}$, donde se observa estructuras arquitectónicas.
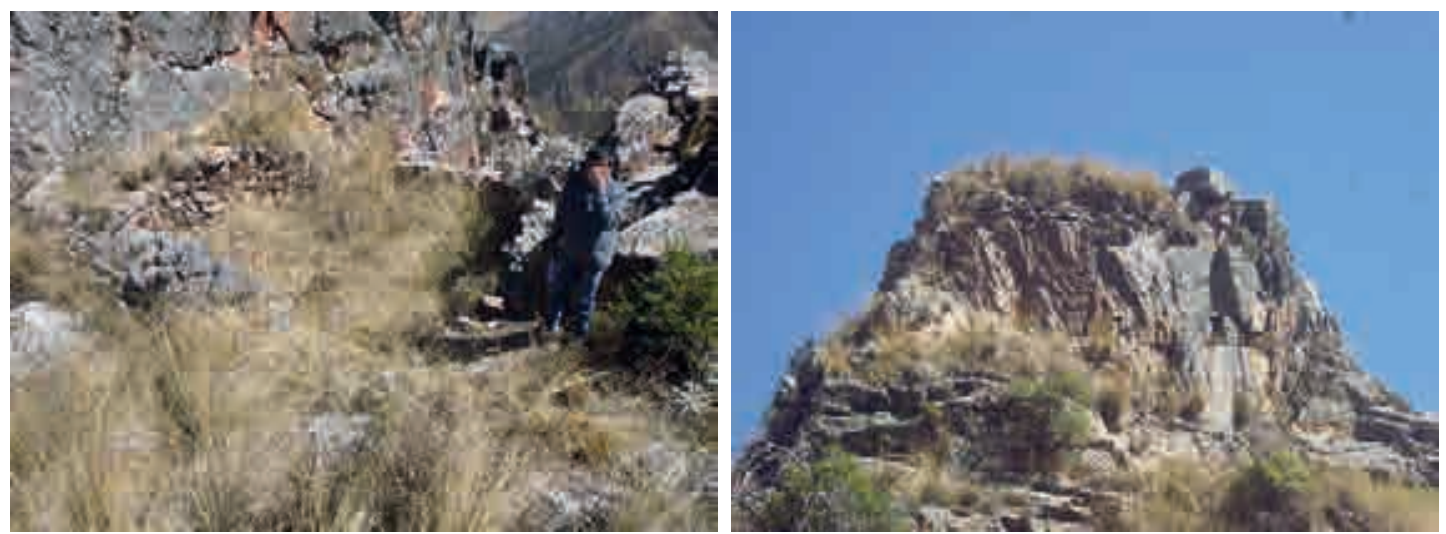

Figura 26 (izquierda): detalle, donde se observa estructuras de plantas cuadrangulares. Figura 27 (derecha): detalle del sector ceremonial, sector $C$.

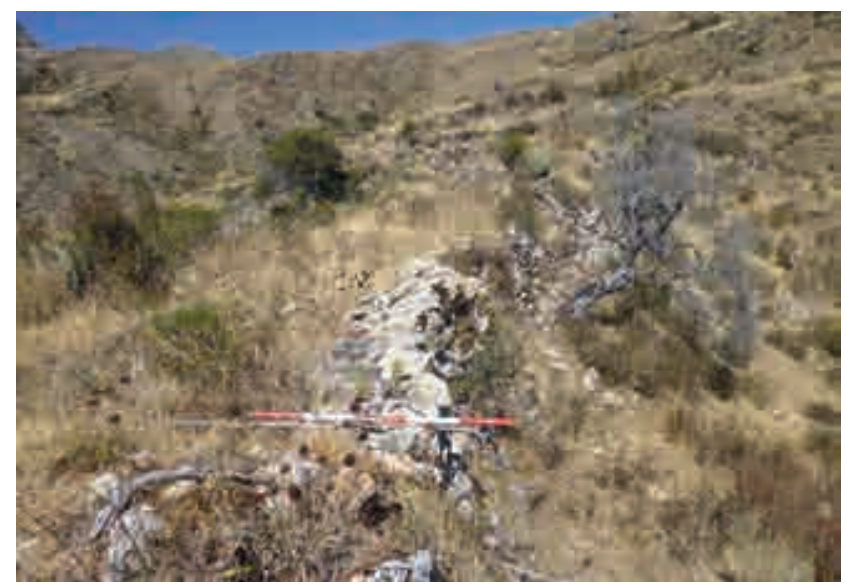

Figura 28: sur a norte, donde se observa el sector D, asociado al sector funerario. 
ancho de los muros es de 0.50 metros por 0.90 metros de alto. Algunos recintos presentan alturas mayores de 1.50 metros. Se identificó algunos recintos con planta en D, de pequeñas dimensiones (de 3 a 4.50 metros de diámetro), los muros son a doble hilera, edificados a base de piedras canteadas del lugar, unidas con argamasa de barro o sin argamasa. En la parte media superior de la cima, sobre una pequeña abra, se identificó dos estructuras cuadrangulares emplazadas sobre una terraza natural rocosa de 4 metros de ancho, 7.60 metros de largo por 1.73 metros de alto, el acceso es mediante dos escalones de rocas que dan a un vano simple.

Se evidenció reocupación arquitectónica, edificándose estructuras sobre cimientos más antiguos. La mayoría de recintos presentan los vanos de acceso orientados hacia el lado noreste, con un ancho de 0.80 metros, 0.60 metros de grosor por 1.10 metro de alto, elaborados con piedras trabajadas unidas con pachillas y argamasa. Se registró aproximadamente 35 estructuras domésticas. Las estructuras cuadrangulares y los de planta ovalada se encuentran adosadas a las estructuras irregulares, de los cuales el 95\% presenta pésimo estado de conservación.

Sector C: Está conformado por un área ceremonial, ubicado en la cima del sitio Torre Torreycco, se observa muros en el farallón superior del cerro.

Sector D: conformado por cistas subterráneas con arquitectura y planta irregular, asociados a áreas domésticas, se ubica en el lado suroeste del sitio, continua inmediatamente del sector C, de 0.60 metros de radio. Se registró aproximadamente 10 cistas subterráneas, el 95\% profanado.

Tipo de sitio: Pueblo pequeño.

Filiación cultural: El sitio corresponde al Intermedio Tardío, con antecedentes de Horizonte Medio (arquitectura de planta en D). Tiene el mismo patrón arquitectónico que Mauca Llacta. Ha sido ocupado hasta el Horizonte Tardío.

Materiales culturales: Se registró fragmentos de cerámica tosca con engobe en superficie exterior crema y rojo pálido. Hay material lítico (mano de moler, artefactos de cuarzo lechoso y cristalino) y material óseo humano.

Estado de conservación: Malo. Las causas de deterioro son naturales y antrópicas.

\section{INKA CHAQUIN}

Ubicación: Se encuentra ubicado en la margen derecha del río Mollebamba, en una ladera rocosa del mismo nombre. Políticamente se ubica en el paraje de Inca Chaquin, Comunidad Campesina de Mollebamba, distrito de Juan Espinoza Medrano, provincia de Antabamba. Se localiza en las coordenadas UTM: 0723861E, 8408291N, a 3812 metros de altitud sobre el nivel del mar. El terreno donde se emplaza el sitio está cubierto de vegetación arbustiva espinosa y cactácea, sobre una lomada rocosa, por los lados suroeste y noroeste presenta acantilados (de unos 300 metros de profundidad). La vía de acceso es mediante camino herradura que dura aproximadamente 30 minutos de caminata desde el sitio Torre Torreycco en dirección suroeste, por camino casi tendido. El sitio arqueológico tiene un área aprox. de 5000 metros cuadrados.

Componentes del sitio: El manejo del espacio se ciñe principalmente a la pequeña elevación de promontorio rocoso, conformado por 33 espacios habitacionales de planta cuadrangular y ovalada, adosados a estructuras más pequeñas de forma irregular y ovalada, algunos se registraron superpuestos sobre muros más antiguos. El recinto mejor conservado tiene 5 metros de diámetro por 1.30 metros de alto, 0.40 metros de ancho de muro, de mampostería ordinaria a doble hilera, elaborada 
en base de material lítico del sitio. Las estructuras de planta cuadrangular, se presenta en un 2\%, las irregulares en un 5\%, y las ovaladas en $93 \%$. Las estructuras de planta ovalada tienen una altura conservada de 1.90 metros, un ancho de muro de 0.60 metros, y un diámetro de entre 5 y 3.50 metros. No se observó espacios libres o abiertos.

Tipo de sitio: doméstico.

Filiación cultural: El sitio corresponde al Intermedio Tardío, probablemente ocupado desde el Horizonte Medio.

Materiales culturales: Se registró un fragmento de cerámica tosca con engobe rojo en superficie exterior y material lítico (cuarzo lechoso y cristalino).

Estado de conservación: malo. Las causas de deterioro son naturales y antrópicas (el pastoreo de ganado). Los recintos se hallan desplomados en un $90 \%$.

\section{Arcopuncu}

Ubicación: Se encuentra ubicado en la margen derecha del río Mollebamba, sobre una terraza aluvial de regulares dimensiones. Políticamente se ubica en el paraje de Arcopuncu, Comunidad Campesina de Mollebamba, distrito de Juan Espinoza Medrano, provincia de Antabamba. Se localiza en las coordenadas UTM: 0725559E, 8401991N, a 3526 metros de altitud sobre el nivel del mar. El terreno donde se emplaza el sitio arqueológico está cubierto de vegetación arbustiva espinosa y cactácea, identificándose las siguientes plantas: ancoquishca, motoy, chilca, gigantón, entre otros. El río Mollebamba se ubica a pocos metros de distancia hacia el lado oeste.

Componentes del sitio: El sitio está conformado por dos sectores:

Sector A: Ubicado hacia el lado norte del asentamiento, en la parte superior de la terraza aluvial. Se aprecia hacia el extremo septentrional del sector, un conjunto de edificaciones de planta cuadrangular de regulares dimensiones, con muros de piedras canteadas unidas con argamasa, aunque muy destruidos. Estas edificaciones están emplazadas sobre plataformas de entre 1 y 2.50 metros de alto. Uno de los recintos mejor conservados, tiene 7.20 metros de largo (eje norte-sur), por 6.70 metros de ancho (eje este-oeste), con sus muros de 1.05 metros de alto, 0.80 metros de grosor, edificados con
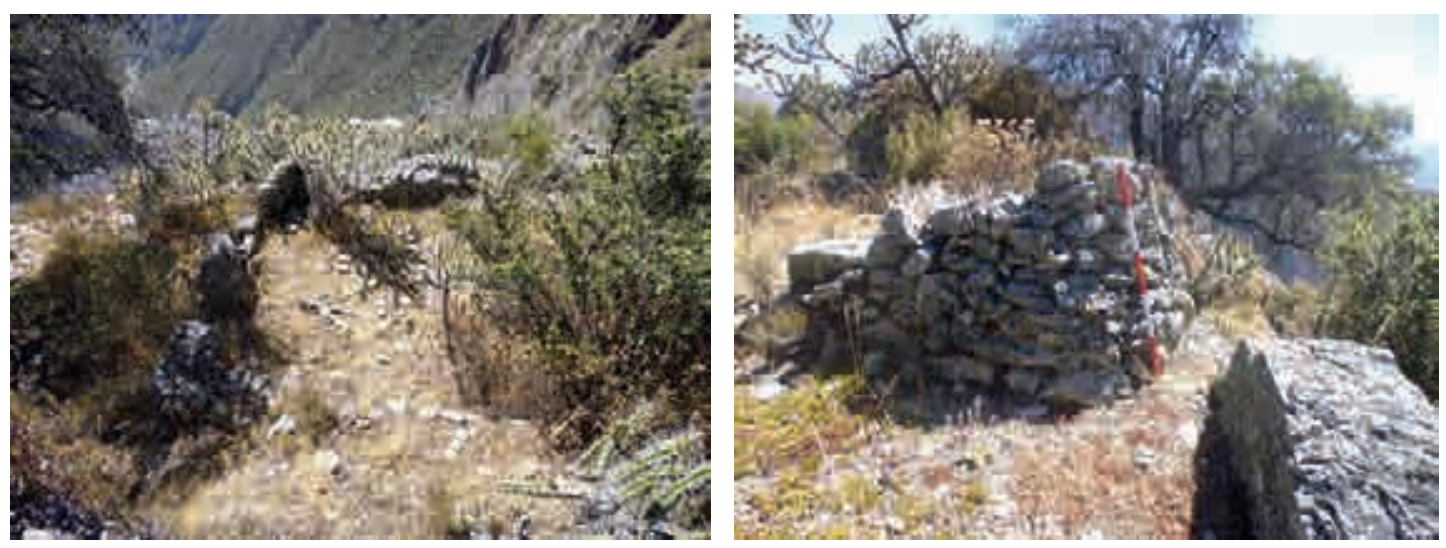

Figura 29 (izquierda): vista de recintos ovalados, cubierto de vegetación espinosa. Figura 30 (derecha): detalle del paramento mejor conservado, donde se observa la mampostería ordinaria. 
piedras canteadas medianas; no identificándose el vano de acceso por el mal estado de conservación. En medio del sector se observa numerosos afloramientos rocosos grandes. En los alrededores de este recinto hay otros cuatro de similares características y dimensiones, aunque en niveles más bajos. Junto a uno de estos recintos de mal estado de conservación se halló una huanca de 0.88 metros de alto y 0.43 metros de diámetro. Hacia el sur de este grupo de recintos hay otros recintos de planta irregular.

Hacia el extremo sur del sector, junto a un pequeño acantilado hay un recinto, el mejor conservado del sector, pero con solo un muro en pie. Este muro está construido a base de piedras canteadas de tamaño regular, unidos con argamasa, de 1.78 metros de alto y 0.62 metros de grosor. En la parte baja del paramento externo hay un nicho cuadrangular de0.26 metros de alto, 0.28 metros de alto y 0.33 metros de profundidad. El recinto es de planta cuadrangular (no perfecto), de 5.75 metros de largo (eje norte-sur) por 4.70 metros de ancho (eje este-oeste). Hacia el sur de este recinto se aprecia un espacio abierto amplio (plaza), la cual ha sido seccionada por un muro moderno.

En medio del sector se observan plataformas sobre las que se emplazan los recintos. Una de estas plataformas tiene 1.60 metros de alto, con muros de contención de piedras canteadas unidas con argamasa, de similar tecnología constructiva que los recintos del sector. La plataforma tiene planta irregular (medio ovalada), de 6.85metros de largo (eje este - oeste), por 3.30metros de ancho (eje norte-sur). En la parte superior de la plataforma no se aprecia ninguna edificación, solo un afloramiento rocoso de regulares dimensiones, lo que nos hace inferir que se trata de un área ceremonial.

Sector B: Se encuentra ubicado hacia el lado sur del asentamiento y debajo de la cima de la terraza aluvial, sobre una ladera que desciende hacia el río Mollebamba. Se observan edificaciones de planta rectangular, dispersas en medio de la tupida vegetación arbustiva espinosa. Se observan algunos edificios de planta irregular y sección semisubterránea cerca de la carretera actual. Uno de los recintos de planta rectangular, ubicado en medio del sector tiene 6.30 metros de largo (eje este-oeste), por 5.10 metros de ancho (eje norte-sur), con muros de piedras canteadas unidas con argamasa, de 0.58 metros de grosor y 1.10 metros de alto, de paredes muy destruidas.

Hacia el lado suroeste del sector se aprecian algunos recintos de planta cuadrangular y rectangular, bien conservados, con muros de más de tres metros de alto, notándose el remate del muro en dos aguas para la cubierta, y con nichos cuadrangulares en los paramentos internos o externos. Uno de estos recintos tiene 5.80 metros de largo (eje este-oeste) por 3.10 metros de ancho (eje norte-sur), preservándose solo el muro este de 3.40 metros de alto y presentando un nicho cuadrangular en el paramento interno, de 0.33 metros de alto, 0.32 metros de ancho y 0.28 metros de profundidad, ubicado a 1.35 metros de altura de la superficie; tiene el remate del muro a dos aguas. Este recinto corresponde a una kallanka del Tawantinsuyu, correspondiendo a un tipo de arquitectura inca local. Hacia el lado noroeste de este recinto, hay otro de similares características.

Tipo de sitio: Asentamiento administrativo.

Filiación cultural: La primera ocupación del sitio corresponde al Intermedio Tardío, con reocupación durante el Tawantinsuyu.

Materiales culturales: Se ha identificado fragmentería cerámica en poca proporción por todo el sitio arqueológico, de naturaleza doméstica, sin decoración. Se han observado algunos pocos batanes.

Estado de conservación: Malo. Las edificaciones están muy destruidas, principalmente por agentes antrópicos. El pastoreo de animales en la zona han colapsado los paramentos. De igual manera, el sismo del año 2001 destruyó gran parte del asentamiento. El principal problema es el colapso de muros. El sitio se encuentra destruido al 95\%. 


\section{QAPAK QOCHA}

Ubicación: Se encuentra ubicado en la margen derecha del río Mollebamba, sobre la ladera de suave pediente del cerro Huamantuco, orientado de este a oeste. Políticamente se ubica en el paraje de Qapak qocha, Comunidad Campesina de Mollebamba, distrito de Juan Espinoza Medrano, provincia de Antabamba. Se localiza en las coordenadas UTM: 0724105E, 8407090N, a 3712 metros de altitud sobre el nivel del mar. El terreno donde se emplaza el sitio arqueológico está cubierto de vegetación arbustiva espinosa y cactácea en todo el sitio, lo que dificulta el acceso al sitio. El río Mollebamba se ubica a pocos metros de distancia hacia el lado oeste. La vía de acceso es mediante trocha carrozable desde Mollebamba en un tramo de 25 minutos, la cual llega hasta la parte alta del sitio, transitando por un camino prehispánico durante 10 minutos. La fuente de agua próxima se ubica a 200 metros al noreste del sitio, correspondiente a una laguna temporal denominada por los pobladores como Qapak qocha, lo que le da el nombre al sitio arqueológico. El sitio tiene un área aprox. de nueve hectáreas.

Componentes del sitio: El sitio está conformado por dos sectores:

Sector A: Ubicado hacia el lado norte y superior del asentamiento, conformado por una edificación de planta rectangular de 19 metros de largo (eje noroeste -sureste) por 5.80 metros de ancho (eje noreste-suroeste). Se trata de una Kallanka Tawantinsuyu, ubicado junto al camino prehispánico que viene de Arequipa y se dirige hacia el Cusco, vía Antabamba y Huaquirca. Al otro lado del camino desciende el sector B, conformado por un sistema de andenerías. La Kallanka está edificada a base de piedras canteadas bien elaboradas en el basamento, unidas con argamasa. El muro noreste es el mejor conservado y tiene 1.50 metros de alto y 0.80 metros de grosor. Los muros presentan doble hilera de piedras con relleno intermedio de tierra y gravilla fina. Por el alto grado de destrucción no se ha podido identificar el vano de acceso y sus características, ni otros elementos murarios. No se ha identificado compartimientos al interior de la Kallanka.

El camino prehispánico es un ramal del Qapaq Ñan, de gran importancia para las relaciones prehispánicas de los diferentes pueblos de la actual provincia de Antabamba, con los de Arequipa y Cusco. En este tramo que se asocia al sitio de Qapak qocha, tiene un ancho promedio de 6 metros, ha sido destruido con maquinaria pesada, por lo que no es posible identificar sus características peculiares.

Sector B: Está conformado por un extenso sistema de andenerías que desciende desde el camino prehispánico hasta el río, en un aproximado de 60 terrazas o graderías escalonadas consecutivas. Las terrazas tienen diferentes dimensiones en ancho y altura, según la topografía del terreno. Por encima del camino y al nivel de la Kallanka también se extienden hasta llegar a la laguna Qapak qocha, ubicado por encima de la Kallanka. Las terrazas tienen muros de contención de 1.20 metros de alto, aproximadamente. Las terrazas se orientan hacia el río (noroeste). En promedio las terrazas tienen 6 metros de ancho.

Tipo de sitio: El sector A: administrativo; el sector B: agrícola.

Filiación cultural: La Kallanka corresponde al Tawantinsuyu, asociado al camino prehispánico; el sector B, también corresponde al Tawantinsuyu, aunque pudo haber sido utilizado y edificado desde el Intermedio Tardío.

Materiales culturales: No se ha identificado ningún material cultural asociado a la arquitectura.

Estado de conservación: Malo. Las causas de deterioro son antrópicas, principalmente el pastoreo y el uso de maquinaria pesada. El sitio se encuentra destruido al 70\%. 


\section{Andenes de Lahua Lahua - Allaujaña}

Ubicación: Se encuentra ubicado en la margen derecha del río Mollebamba, sobre la ladera de regular pendiente de los cerros Lahua Lahua y Allaujaña, orientado de este a oeste. Políticamente se ubica en el paraje de Lahua Lahua, Comunidad Campesina de Mollebamba, distrito de Juan Espinoza Medrano, provincia de Antabamba. Se localiza en las coordenadas UTM: 07259065E, 8402278N, a 3580 metros de altitud sobre el nivel del mar. El terreno donde se emplaza el sitio arqueológico está utilizado para la actividad agrícola sobre las terrazas. El río Mollebamba se ubica a pocos metros de distancia hacia el lado oeste. La vía de acceso es mediante trocha carrozable desde Mollebamba en un tramo de 15 minutos, la cual llega hasta la parte baja del sitio. La fuente de agua próxima se ubica por encima de los andenes. El sitio tiene un área aprox. de tres hectáreas.

Componentes del sitio: El sitio está conformado por dos sectores de andenerías:

Sector A: Corresponde al sector de Lahua Lahua, ubicado hacia el lado norte, en la ladera del cerro del mismo nombre. Presenta cerca de 25 terrazas escalonadas, con tres árboles de eucalipto en la parte central. Las terrazas tienen en promedio 1.50 metros de alto y 5.50 metros de ancho.

Sector B: Corresponde al sector de Allaujaña, ubicado hacia el lado sur, en la ladera del cerro del mismo nombre. Presenta cerca de 30 terrazas escalonadas. Las terrazas tienen en promedio 2.00 metros de alto y 6.00 metros de ancho. Tanto este sector, como el anterior siguen siendo utilizados como zonas de cultivo.

Tipo de sitio: sistema agrícola.

Filiación cultural: Intermedio Tardío y Tawantinsuyu.

Materiales culturales: No se ha identificado material cultural en superficie asociado a los andenes.

Estado de conservación: Regular. El sitio se encuentra destruido al 50\%.

\section{SAyAs Marka}

Ubicación: Se encuentra ubicado en la margen derecha del río Mollebamba, sobre una planicie de suave pendiente hacia el lado sur, orientado de oeste a este. Políticamente se ubica en el paraje de Sayasmarka, Comunidad Campesina de Mollebamba, distrito de Juan Espinoza Medrano, provincia de Antabamba. Se localiza en las coordenadas UTM: 0723455E, 8407830N, a 3705 metros de altitud sobre el nivel del mar. Hacia el lado noroeste existe un acantilado rocoso de aproximadamente 200 metros. El terreno donde se emplaza el sitio arqueológico está cubierto de vegetación arbustiva espinosa y cactácea en la parte alta (sector A), lo que dificulta el acceso. El río Mollebamba se ubica hacia el lado oeste. La vía de acceso es mediante trocha carrozable desde Mollebamba en un tramo de 30 minutos, la cual llega hasta la parte baja del sitio. La fuente de agua próxima se ubica a 500 metros al sur del sitio, correspondiente a una laguna temporal denominada por los pobladores como Qapak qocha. El sitio tiene un área aprox. de dos hectáreas.

Componentes del sitio: El sitio está conformado por tres sectores:

Sector A: Ubicado hacia el lado oeste y superior del asentamiento, conformado por un conjunto de edificaciones de planta ovalada y algunas irregulares, emplazadas sobre plataformas de diferentes altitudes. Son cerca de 40 estructuras en este sector, edificados a base de piedras canteadas unidas con argamasa, con muros dobles, de 0.40 metros de ancho y 1.20 metros de alto. El diámetro de los recintos es de 3.50 metros en promedio. No se identificaron los vanos por el mal estado de conservación. Los recintos se distribuyen de a dos o tres en cada plataforma, conformando conjuntos. 
Sector B: Está conformado por un área de espacios libres de planta rectangular, emplazados sobre amplias plataformas. Se trata de tres espacios: el espacio A tiene 45 metros de largo (eje norte-sur) por 40 metros de ancho (eje este-oeste); el espacio B se ubica al norte del espacio A, en la parte central del sector, de 40 metros de largo (eje este-oeste) por 30 metros de ancho (eje norte - sur); mientras que el espacio C se ubica al extremo norte, de 40 metros de largo (eje este-oeste) por 35 metros de ancho (eje norte-sur). Estos espacios se dividen por los muros de contención de las terrazas donde se emplazan. Por su parte el sector B se divide del A por un muro divisorio. En el espacio C se observan siete construcciones de planta ovalada, deterioradas en un $80 \%$, de características similares a las del sector A, aunque se emplazan sobre la misma plataforma. El espacio B es totalmente libre, por lo que se trata de un área de reunión de la comunidad. El espacio A tiene una estructura funeraria tipo chullpa, ubicada en la esquina suroeste, la cual tiene planta cuadrangular, de 5.20 metros de largo (eje este-oeste, por 5.05 metros de ancho (eje norte-sur) y 2.55 metros de altura. Esta chulpa está edificada con piedras canteadas unidas con argamasa. Está conformada por un solo nivel y una sola cámara interna. Actualmente se utiliza esta chullpa como almacén de herramienta de los agricultores de la zona, pues ha sido saqueada. Presenta un vano hacia el lado norte, de 0.95 metros de ancho y 1.20 metros de alto.

Sector C: Está ubicado al lado oriental del sitio, conformado por una plataforma de planta rectangular, sobre la cual se emplaza un área pública (plaza), de 50 metros de largo (eje sur - norte) por 40 metros de ancho (eje este -oeste). La plataforma tiene 0.50 metros de alto en el lado este y 0.30 metros en el lado oeste, con respecto a la superficie natural del cerro; edificada con muros de contención a base de piedras canteadas grandes y medianas, unidas con argamasa. Se observa en la parte central, tres afloramientos rocosos de medianas dimensiones, que habrían cumplido función ceremonial.

Tipo de sitio: Pueblo o marca. Funciones administrativas, domésticas, ceremoniales y funerarias.

Filiación cultural: Intermedio Tardío y Horizonte Tardío.

Materiales culturales: Se ha identificado en la superficie del sector A regular cantidad de fragmentería cerámica de naturaleza doméstica.

Estado de conservación: Malo. Los sectores A y B se encuentran en mal estado, mientras que el sector $C$ en regular. Las causas de deterioro son antrópicas, principalmente el pastoreo. El sitio se encuentra destruido al 70\%. Los problemas estructurales identificados en el sector A son: pandeo, pérdida de mortero, grietas y colapso de muros.

\section{ANDENES DE LAMBRAMANI}

Ubicación: Se encuentra ubicado en la margen derecha del río Mollebamba, sobre la ladera de regular pendiente del cerro Lambramani, orientado de este a oeste. Políticamente se ubica en el paraje de Lambramani, Comunidad Campesina de Mollebamba, distrito de Juan Espinoza Medrano, provincia de Antabamba. Se localiza en las coordenadas UTM: 0725301, 8403224N, a 3419 metros de altitud sobre el nivel del mar. El terreno donde se emplaza el sitio arqueológico está utilizado para la actividad agrícola sobre las terrazas. El río Mollebamba se ubica a pocos metros de distancia hacia el lado oeste. La vía de acceso es mediante trocha carrozable desde Mollebamba en un tramo de 15 minutos, la cual llega hasta la parte baja del sitio. El sitio tiene un área aprox. de doce hectáreas.

Componentes del sitio: El sitio está conformado por un sistema de andenerías, de veinte graderías escalonadas y continuas, en regular estado de conservación, con muros de contención construidos con piedras canteadas unidas con argamasa.

Tipo de sitio: sistema agrícola. 
Filiación cultural: Intermedio Tardío y Tawantinsuyu.

Materiales culturales: No se ha identificado material cultural en superficie asociado a los andenes.

Estado de conservación: Regular. El sitio se encuentra destruido al 50\%.

\section{Andenes de PascañI}

Ubicación: Se encuentra ubicado en la margen derecha del río Mollebamba, sobre la ladera de regular pendiente de los cerros Lahua Lahua y Allaujaña, orientado de este a oeste. Políticamente se ubica en el paraje de Lahua Lahua, Comunidad Campesina de Mollebamba, distrito de Juan Espinoza Medrano, provincia de Antabamba. Se localiza en las coordenadas UTM: 0725019E, 8403456N, a 3712 metros de altitud sobre el nivel del mar. El terreno donde se emplaza el sitio arqueológico está utilizado para la actividad agrícola sobre las terrazas. El río Mollebamba se ubica a pocos metros de distancia hacia el lado oeste. La vía de acceso es mediante trocha carrozable desde Mollebamba en un tramo de 15 minutos, la cual llega hasta la parte baja del sitio. La fuente de agua próxima se ubica por encima de los andenes. El sitio tiene un área aprox. de tres hectáreas.

Componentes del sitio: El sitio está conformado por un montículo natural de planta ovalada, sobre el cual se han edificado desde la base hasta la cima, terrazas agrícolas continuas, identificándose 15 groserías continuas.

Tipo de sitio: sistema agrícola.

Filiación cultural: Intermedio Tardío y Tawantinsuyu.

Materiales culturales: No se ha identificado material cultural en superficie asociado a los andenes.

Estado de conservación: Regular. El sitio se encuentra destruido al 60\%.

\section{B. Sitios arqueológicos de la Comunidad Campesina de Calcauso}

\section{Andenes de Anaropata}

Ubicación: Se encuentra ubicado en la margen izquierda del río Mollebamba, sobre el piso del cerro Calcauso a orilla del valle. El relieve del terreno es irregular con pendiente pronunciada hacia el río, orientado de este a oeste. Políticamente se ubica en el paraje de Anaropata, Comunidad Campesina de Calcauso, distrito de Juan Espinoza Medrano, provincia de Antabamba. Se localiza en las coordenadas UTM: 0725305E, 8401261N, a 3550 metros de altitud sobre el nivel del mar. El terreno donde se emplaza el sitio arqueológico está utilizado para la actividad agrícola sobre las terrazas. El río Mollebamba se ubica en límite directo por el lado oriental. La vía de acceso es mediante camino de herradura a 5 minutos desde el pueblo de Calcauso. La fuente de agua próxima se ubica en el río mismo. El sitio tiene un área aprox. de una hectárea.

Componentes del sitio: El sitio está conformado por un pequeño sistema de andenerías correspondiente a los andenes de Anaropata. Presenta aprox. 20 terrazas escalonadas, interrumpidas e irregulares; la mayoría se desplaza en sentido norte sur, actualmente tiene límite directo con el cementerio moderno de calcauso por el lado oeste. En el lado este del sitio se registró una cista funeraria de planta circular con arquitectura subterránea, huaqueada y edificado con piedras labradas pequeñas unidas con mortero, emplazado sobre un espacio plano, de 0.86 metros de profundidad por 0.78 metros de diámetro. En los alrededores se halló fragmentos de cerámica en regular cantidad. Presenta arboles de eucaliptos al filo del camino. Las terrazas tienen en promedio 16 metros de largo, de 8 a 6 
metros de ancho, por 1.50 metros de alto. Las cabeceras de los muros presentan remodelación moderna.

Tipo de sitio: sistema agrícola y una cista funeraria.

Filiación cultural: Intermedio Tardío y Tawantinsuyu.

Materiales culturales: Se identificó fragmentos de cerámica tosca como bordes, asas y cuerpos, las cuales presentan pasta gruesa con antiplásticos de granito, de superficie exterior pulida de color rojizo y anaranjado. Se halló un fragmento de color negro, así como material lítico (obsidiana, cuarzo) y material óseo.

Estado de conservación: Malo. El sitio se encuentra destruido al 60\% y reutilizado el 30\% para la agricultura, también funciona como echadero de ganado.

\section{QOLLPANA}

Ubicación: Se encuentra ubicado en la margen izquierda del río Mollebamba, sobre una pequeña planicie natural que se extiende en sentido norte-sur. Políticamente se ubica en el paraje de Qollpana, Comunidad Campesina de Calcauso, distrito de Juan Espinoza Medrano, provincia de Antabamba. Se localiza en las coordenadas UTM: 0724777E, 8395935N, a 3556 metros de altitud sobre el nivel del mar. El terreno donde se emplaza el sitio arqueológico es una pequeña planicie que se utiliza como estancia para la crianza de ganado, donde casi no es notoria las evidencias prehispánicas. La persona que vive en esta estancia cuenta que hace 10 años atrás recuperaron el contexto funerario completo de un individuo asociado a dos vasijas. La vía de acceso es mediante un camino de herradura por dos horas de caminata desde Calcauso, en sentido sur, el camino es tendido y va casi por la orilla del río. La fuente de agua principal es el río, aunque la planicie es ligeramente pantanosa, presentando afloramiento de agua salitrosa. El sitio tiene un área aprox. de dos hectáreas, cubierta de vegetación herbácea.

Componentes del sitio: El sitio Qollpana está conformado por dos sectores:

Sector A: Corresponde a la cimentación de muros, ubicado en la margen derecha de la quebrada Qollpana, actualmente existe una estancia para la crianza de ganados.

Sector B: corresponde a un conjunto de andenes escalonados, ubicado en la margen izquierda de la quebrada, que se desplaza desde el piso hacia una ladera de suave pendiente en sentido este-oeste. Se evidenció 10 terrazas, donde el seccionamiento de los andenes es continua o extendido e irregulares. Toda el área perimétrica se encuentra encerrado por corrales modernos y utilizado para agricultura actual. Hay también una casa de adobe moderno, con plantas de eucalipto en los alrededores. Los muros de las terrazas son de piedras canteadas en mampostería simple.

Tipo de sitio: sistema agrícola y basamentos de muro.

Filiación cultural: Intermedio Tardío y Tawantinsuyu.

Materiales culturales: No se identificó material cultural mueble.

Estado de conservación: Malo. El sitio se encuentra destruido al 60\% y reutilizado el 40\% para la agricultura y ganadería.

\section{AnTAQASA}

Ubicación: Se encuentra ubicado en las punas de Antaqasa, en la margen izquierda del río Mollebamba, sobre la ceja de una lomada de suave pendiente que se extiende hacia el lado este y de pen- 


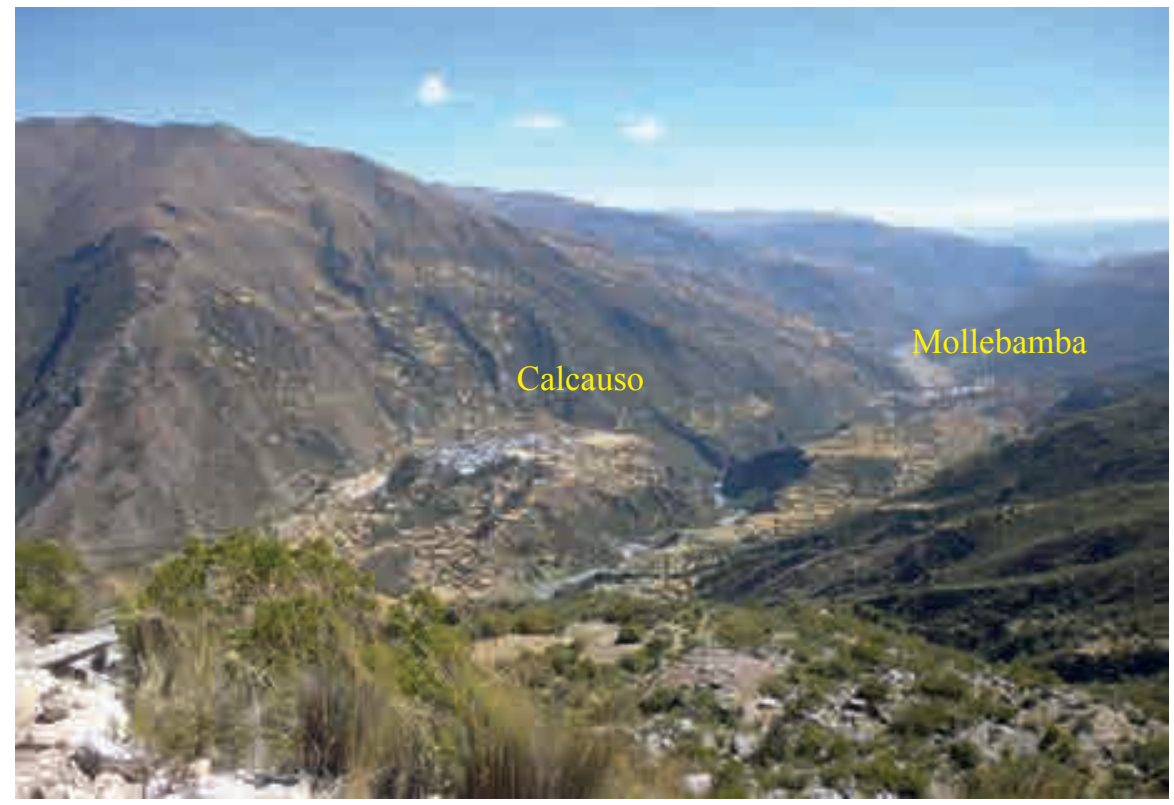

Figura 31: vista panorámica de los pueblos de Calcauso y Mollebamba, visto desde el sitio arqueológico Cconopani. Nótese los sistemas de andenerías que circundan los pueblos.

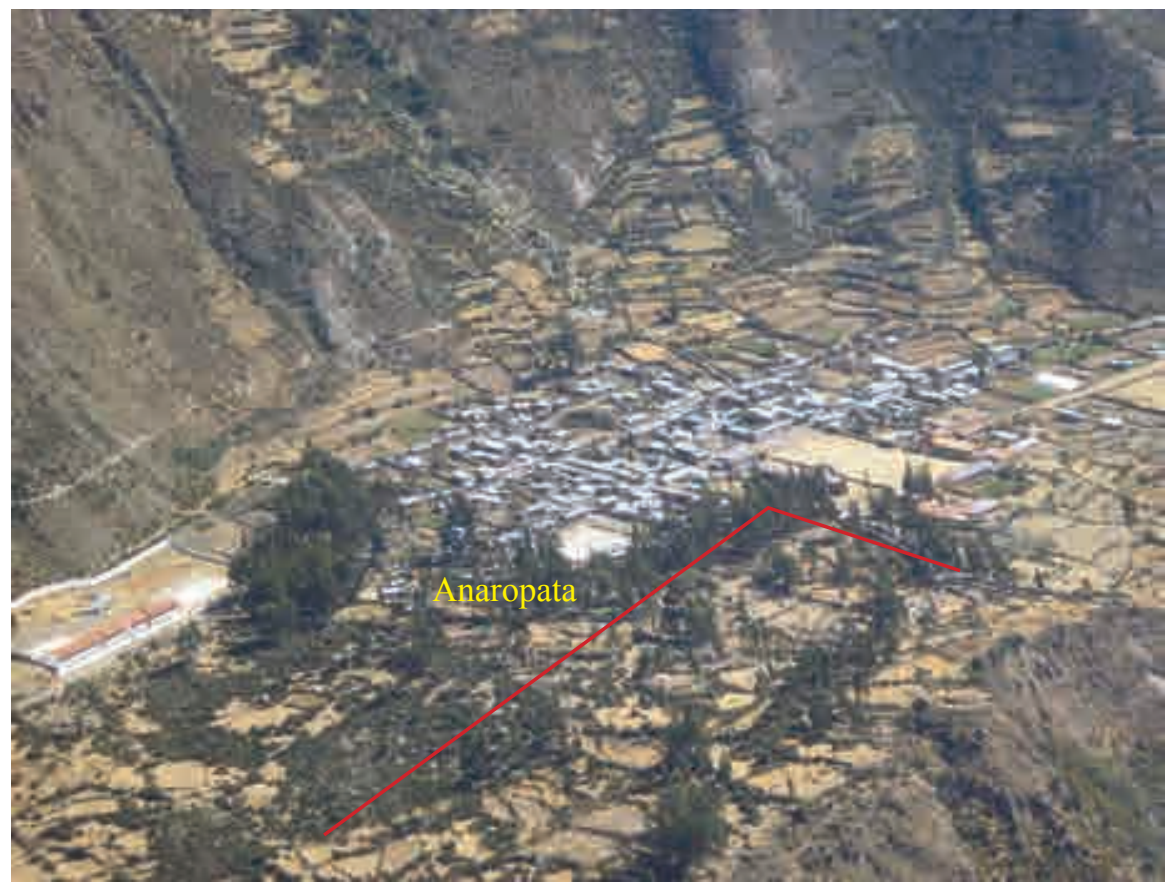

Figura 32: vista panorámica del sitio arqueológica Anaropata. 

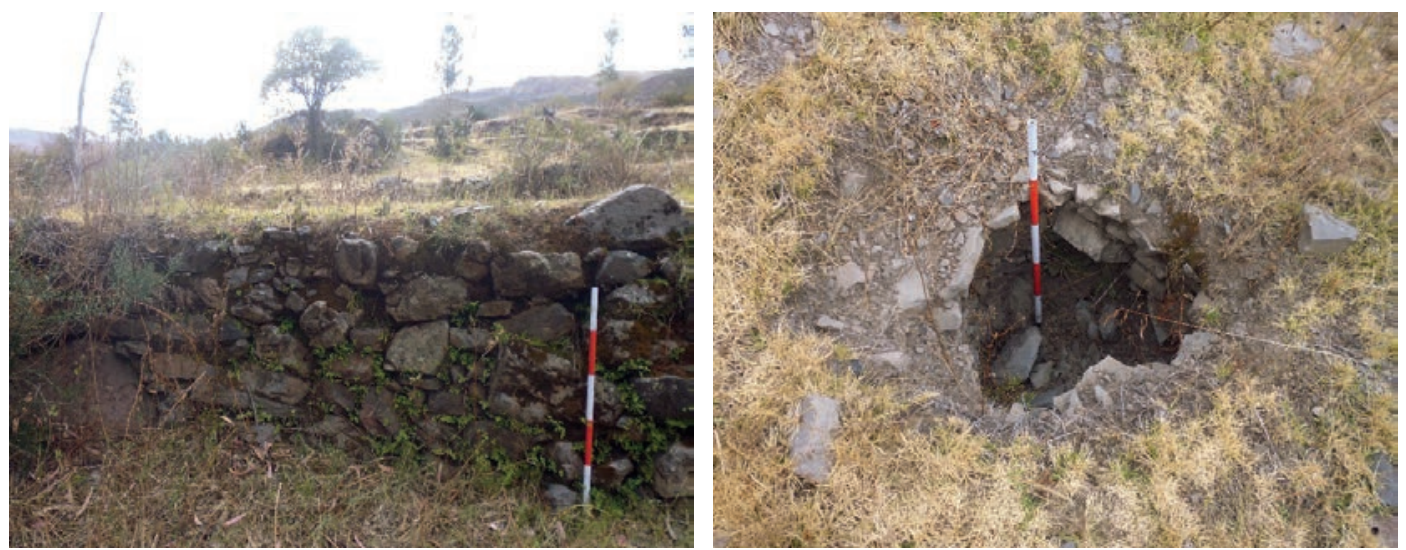

Figura 33 (izquierda): Foto detalle de andenes prehispánicos de Anaropata. Figura 34 (derecha): Vista de cista subterránea huaqueada, ubicado en una plataforma de anden.
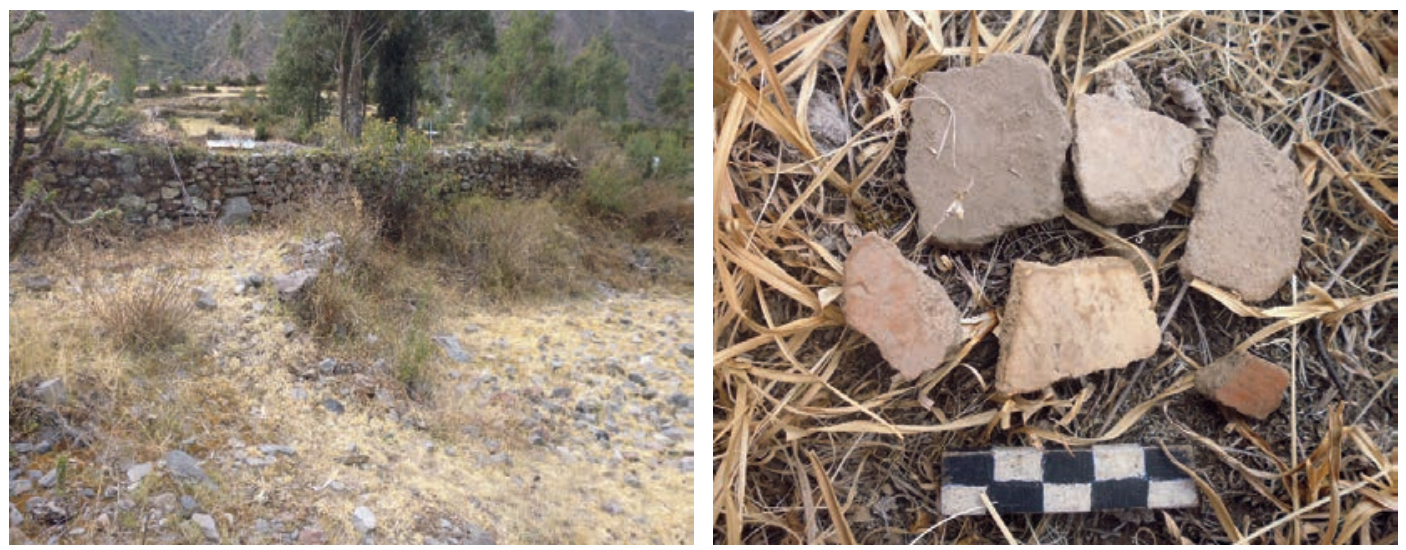

Figura 35 (izquierda): Vista oeste este, de andenes, donde se observa rodeado de árboles de eucalipto. Figura 36 (derecha): Cerámica doméstica, pulido de color crema.
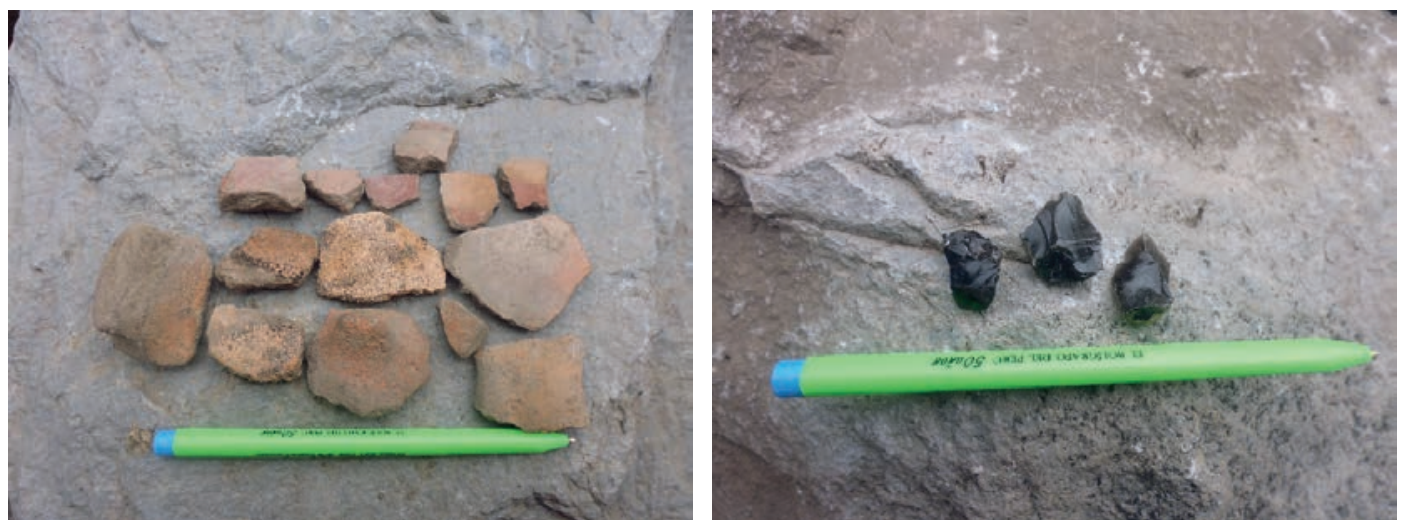

Figura 37 (izquierda): Cerámica doméstica, de pasta tosca, color anaranjado pálido. Figura 38 (derecha): Vista de fragmentos de obsidiana. 
diente pronunciada, ubicada hacia el suroeste de la quebrada Saurihuaycco, con vista directa al cerro Nanrrapaya, orientado de este a oeste. Políticamente se ubica en el paraje de Antaqasa, Comunidad Campesina de Calcauso, distrito de Juan Espinoza Medrano, provincia de Antabamba. Se localiza en las coordenadas UTM: 0723261E, 8393322N, a 4154 metros de altitud sobre el nivel del mar. El terreno donde se emplaza el sitio arqueológico está cubierto de vegetación gramínea de ichu y choqos. El río Mollebamba se ubica aprox. a 5 kilómetros al lado este. La vía de acceso es mediante un camino de herradura cuesta arriba, aprox 3 horas de caminata desde el sitio Qollpana, camino que llega hasta la parte alta de las punas mencionadas. La fuente de agua próxima se ubica a 300 metros al sureste del sitio, correspondiente a un bojedal que discurre de este a oeste, que nace desde la parte alta de Antaqasa. El sitio tiene un área aprox. de 200 metros cuadrados.

Componentes del sitio: El sitio Antaqasa se compone de dos sectores:

Sector A: Está conformado por cistas funerarias subterráneas, ubicado en la parte superior de un abra, sobre un pequeño relieve plano. Está conformado por 14 cámaras funerarias de forma circular e irregular, donde pocos aún conservan los techos originales, estructurados con vigas de piedra sin labrar y sobre estas se aplicaba torta de barro como un sello. Los muros de estas cistas subterráneas fueron hechos con piedras de campo, unidas con mortero de barro, tiene un ancho promedio de un metro, un metro de diámetro en la boca y 1.20 metros de profundidad. Cada tumba guarda una distancia mínima de 2 metros, el 95\% se encuentra profanada. Al interior se evidenció restos de material óseo humano en estado de conservación muy frágil.

Sector B: Está ubicado aproximadamente a 200 metros al este del sector A, en una pequeña superficie plana, conformado por cinco estructuras arquitectónicas. El área domestica más grande es de planta cuadrangular, de 10 por 9 metros de lado, al cual se asocian estructuras más pequeñas de formas circulares que tiene de 6 a 7 metros de diámetro. Solo se conserva los basamentos de las estructuras, en su totalidad se halla cubierto de vegetación herbácea de ichus.

Tipo de sitio: El sector A: área funeraria; el sector B: área doméstica.

Filiación cultural: las cistas subterráneas y el área doméstica corresponden al periodo Intermedio Tardío, aunque pudo haber sido utilizado y edificado desde finales del Horizonte Medio.

Materiales culturales: se identificó material óseo humano en las cistas subterráneas; mientras que en el sector B, no se identificó ningún material cultural asociado a la arquitectura.

Estado de conservación: Malo. Las causas de deterioro son antrópicas, principalmente el pastoreo. El 95\% de las tumbas se identificaron profanadas, las estructuras arquitectónicas en el $98 \%$ se encuentran colapsadas, donde solo se evidencia el basamento de los muros.

\section{QARPOSA}

Ubicación: Se encuentra ubicado en la margen derecha del río Yanahuara (margen izquierda del río Mollebamba), en la comunidad de Calcauso, distrito de Juan Espinoza Medrano, provincia de Antabamba. Para llegar al sitio se toma el camino que sale de la comunidad de Calcauso hacia el caserío de Antacuna Huanca y Cotahuasi (Arequipa), caminando por 40 minutos. Está emplazado junto a un acantilado, al interior de un abrigo rocoso ubicado en la parte baja de un elevado cerro, cubierto de vegetación arbustiva espinosa muy tupida y cactus, que hacen muy difícil el acceso.

Descripción: El sitio está conformado por un pequeño abrigo rocoso de 6 metros de largo por 0.60 metros de altura. En la parte interna se observa al interior de este abrigo se observan adosadas a la 


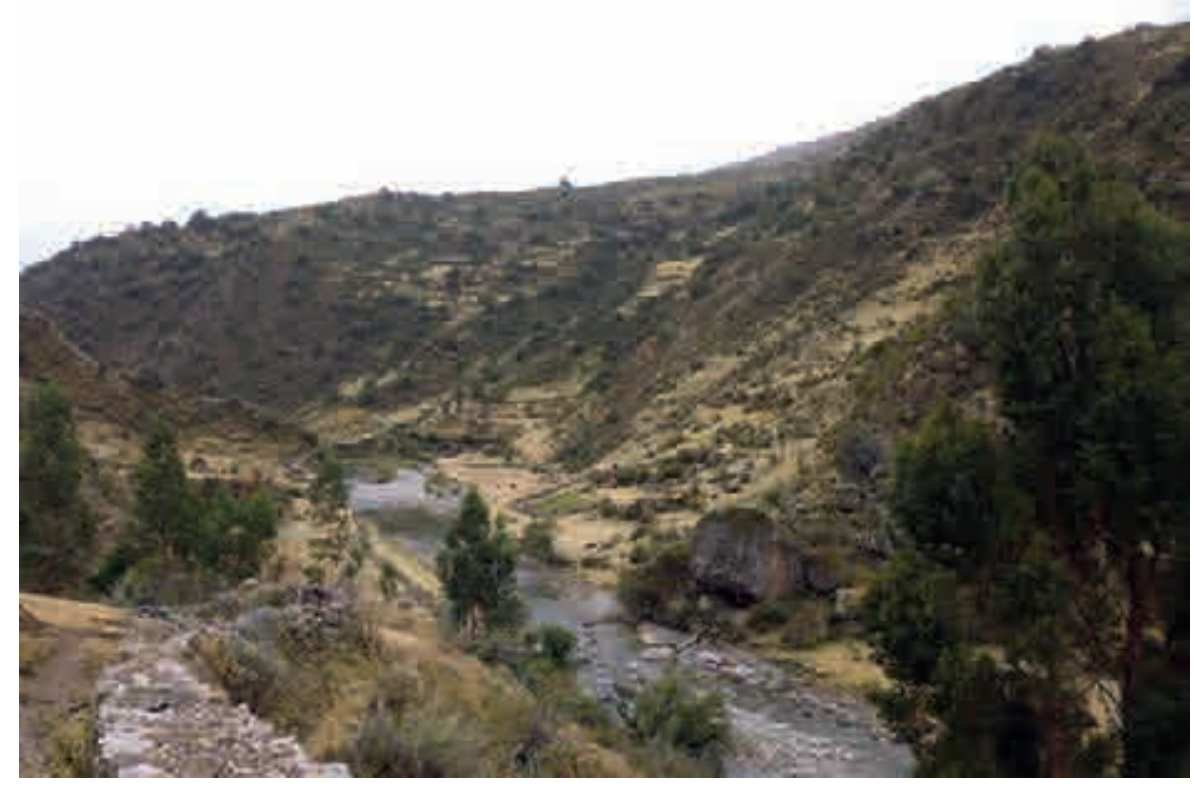

Figura 39: vista de andenes prehispánicos de Qollpana, ubicado en la margen derecha del río.

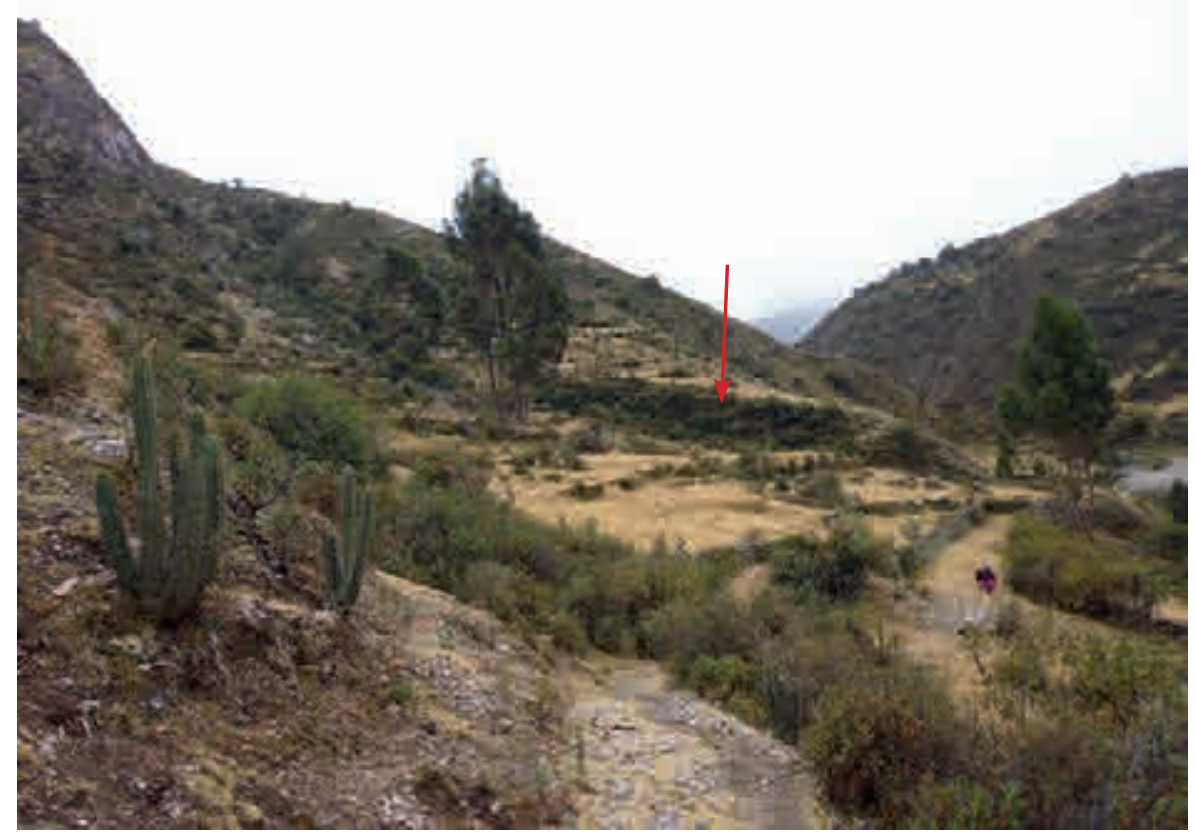

Figura 40: vista de andenes de Qollpana, ubicado en la margen izquierda del río. 